\title{
Templated $\alpha$-Synuclein Inclusion Formation Is Independent of Endogenous Tau
}

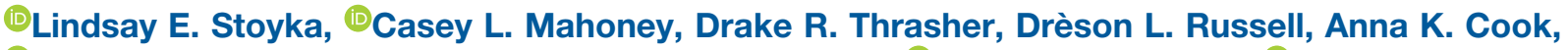 \\ (D)Anner T. Harris, Ashwin Narayanan, Tiara P. Janado, David G. Standaert, ${ }^{\circledR}$ Erik D. Roberson, and \\ (DLaura A. Volpicelli-Daley
}

https://doi.org/10.1523/ENEURO.0458-20.2021

Center for Neurodegeneration and Experimental Therapeutics, University of Alabama at Birmingham, Birmingham, AL 35294

\begin{abstract}
Synucleinopathies including Parkinson's disease (PD) and dementia with Lewy bodies (DLB) are characterized by neuronal intracellular inclusions of $\alpha$-synuclein. PD dementia (PDD) and DLB are collectively the second most common cause of neurodegenerative dementia. In addition to associated inclusions, Lewy body diseases (LBDs) have dopaminergic neurodegeneration, motor defects and cognitive changes. The microtubule-associated protein tau has been implicated in LBDs, but the exact role of the protein and how it influences formation of $\alpha$-synuclein inclusions is unknown. Reducing endogenous tau levels is protective in multiple models of Alzheimer's disease (AD), tauopathies, and in some transgenic synucleinopathy mouse models. Recombinant $\alpha$-synuclein and tau proteins interact in vitro. Here, we show tau and $\alpha$-synuclein colocalize at excitatory presynaptic terminals. However, tau heterozygous and tau knock-out mice do not show a reduction in fibril-induced $\alpha$-synuclein inclusions formation in primary cortical neurons, or after intrastriatal injections of fibrils at 1.5 month or sixmonths later. At sixmonths following intrastriatal injections, wild-type, tau heterozygous and tau knock-out mice showed a 50\% reduction in dopamine neurons in the substantia nigra pars compacta (SNc) compared with mice injected with $\alpha$-synuclein monomer, but there were no statistically significant differences across genotypes. These data suggest the role of tau in the pathogenesis of LBDs is distinct from AD, and Lewy pathology formation may be independent of endogenous tau.
\end{abstract}

Key words: dementia; Lewy; neurodegenerative; Parkinson's disease; synuclein; tau

\section{Significance Statement}

Variations in the MAPT H1 haplotype are associated with Parkinson's disease (PD), but it is possible that other genes within the $\mathrm{H} 1$ haplotype play a role in PD etiology. In vitro studies show $\alpha$-synuclein and tau interact, leading to synergistic fibrillization. $\alpha$-Synuclein and tau can co-exist in Lewy bodies. Tau reduction is protective in models of Alzheimer's disease (AD) and tauopathies and has been suggested as a therapeutic strategy for PD. Here, we show reduction of endogenous tau does not influence formation of templated $\alpha$-synuclein inclusion formation or loss of dopamine neurons, suggesting that therapeutics directed to tau for PD may be more complicated than tau reduction.

\section{Introduction}

Neuronal synucleinopathies include Parkinson's disease (PD), PD dementia (PDD), and dementia with Lewy bodies (DLB), referred to as Lewy body diseases (LBDs).

Received October 24, 2020; accepted April 14, 2021; First published May 10, 2021.

The authors declare no competing financial interests.
LBDs are characterized by intracellular inclusions composed mostly of $\alpha$-synuclein, found in the soma, termed

Author contributions: L.E.S., D.G.S., E.D.R., and L.A.V.-D. designed research; L.E.S., C.L.M., D.R.T., D.L.R., A.K.C., A.T.H., A.N., and T.P.J. performed research; E.D.R. contributed unpublished reagents/analytic tools; L.E.S., C.L.M., A.K.C., A.T.H., A.N., and L.A.V.-D. analyzed data; L.E.S., C.L.M., D.R.T., E.D.R., and L.A.V.-D. wrote the paper. 
Lewy bodies, and axons, called Lewy neurites (Spillantini et al., 1997, 1998). In addition to localizing to brain areas important for movement such as the substantia nigra pars compacta (SNc), Lewy pathology is found in the cortex and limbic brain regions where it may contribute to cognitive and psychiatric symptoms (Mattila et al., 1998; Braak et al., 2003, 2005; Jellinger, 2009; Del Tredici and Braak, 2013; Hall et al., 2014; Irwin et al., 2017; Jellinger and Korczyn, 2018).

Although the majority of LBDs are idiopathic disorders, genetic factors are implicated in the pathogenesis and risk factors of these diseases. The gene for $\alpha$-synuclein, SNCA, has the highest population attributable risk (PAR) in genetic studies of PD risk, and mutations or multiplications in this gene cause early-onset familial PD (Blauwendraat et al., 2020). A strong association of variations in MAPT 17q.21.31 locus $\mathrm{H} 1$ haplotype also occurs with PD (Blauwendraat et al., 2020). However, many genes are located within this locus, and it remains unclear whether MAPT alone is the primary culprit.

The protein product of $M A P T$, microtubule-associated protein tau, forms hyperphosphorylated neurofibrillary tangles (NFTs), one of the main characteristics of Alzheimer's disease (AD). The role of tau in synucleinopathies is poorly understood. The presence of both Lewy pathology and NFTs composed of tau in the cortex are the strongest correlate of cognitive decline in PDD (Irwin et al., 2017; Coughlin et al., 2019). In vitro experiments demonstrate the microtubule binding domain of tau directly interacts with the $\mathrm{C}$ terminus of $\alpha$-synuclein, promoting synergistic fibrillization of both proteins (Giasson et al., 2003; Dasari et al., 2019). Electron microscopy shows that tau aggregates are found in the same neuron as those harboring Lewy pathology (Duda et al., 2002; Ishizawa et al., 2003). These data suggest that an interaction of $\alpha$-synuclein and tau may contribute to the etiology of PD.

Reduction of tau is protective in models of $A D$ and other tauopathies reducing cognitive deficits, seizure susceptibility, and premature mortality (Roberson et al., 2007; DeVos et al., 2017, 2018). The role of tau reduction in PD and LBDs has been more challenging to elucidate. In mice overexpressing human $\alpha$-synuclein, absence of tau rescues memory deficits as tested by Barnes maze,

This work was supported by the Department of Defense Parkinson's Research Program Grant PD15032 and National Institutes of Health (NIH) National Institute of Neurological Disorders and Stroke (NINDS) Grant R01 NS102257 (to L.A.V.-D.), the NIH NINDS Grant R01NS075487 (to E.D.R.), the NIH Grant P50 NS108675 (to D.G.S.), and the National Institute on Aging Grant F30AG058458 and the National Institute of General Medical Sciences T32 MSTP Training Grant GM008361 (to L.E.S.).

Acknowledgements: We thank Valentina Krendelchtchikova for her help with purifying recombinant $\alpha$-synuclein and Dr. Karen Gamble for advice on statistics. We also thank University of Alabama at Birmingham's High Resolution Imaging Core, which provides the confocal microscope for the expansion microscopy images.

Correspondence should be addressed to Laura A. Volpicelli-Daley at Ivolpicellidaley@uabmc.edu.

https://doi.org/10.1523/ENEURO.0458-20.2021

Copyright (C) 2021 Stoyka et al.

This is an open-access article distributed under the terms of the Creative Commons Attribution 4.0 International license, which permits unrestricted use, distribution and reproduction in any medium provided that the original work is properly attributed. contextual fear conditioning, and novel object recognition (Singh et al., 2019). Antibodies to oligomeric tau reduce memory defects and Lewy-body like pathology in mice overexpressing the A53T mutant form of $\alpha$-synuclein (Gerson et al., 2018). In contrast, absence of tau did not prevent templated spreading of misfolded $\alpha$-synuclein, or dopamine neuron loss and associated motor deficits in toxin-induced and transgenic models of human- $\alpha$-synuclein overexpression (Morris et al., 2011; Gratuze et al., 2019; Jiao et al., 2020; Bassil et al., 2021). The effect of tau reduction in PD models, therefore, differs from $A D$ models, and further characterization is necessary.

Small seeds of fibrillar $\alpha$-synuclein corrupt endogenous $\alpha$-synuclein to form inclusions biochemically and morphologic resembling those found in PD and DLB (VolpicelliDaley et al., 2011; Luk et al., 2012; Paumier et al., 2015; Froula et al., 2019; Sorrentino et al., 2019). Use of intrastriatal injections of recombinant $\alpha$-synuclein fibrils recapitulates Lewy-like pathology in brain regions critical to LBDs such as the SNc, cortex and amygdala. Because fibrils induce the formation of inclusions from endogenously expressed $\alpha$-synuclein, this model allows us to use tau heterozygous and tau knock-out mice to determine the role of tau reduction in template $\alpha$-synuclein inclusion formation.

Here, our goal was to investigate whether tau reduction influences templated $\alpha$-synuclein inclusion formation. First, we show that $\alpha$-synuclein and tau colocalize at the presynaptic terminal of excitatory neurons. However, neither tau heterozygous nor tau knock-out mice show reductions in seeded $\alpha$-synuclein inclusions or loss of dopamine neurons in the SNc. Thus, reduction of endogenous tau does not appear to prevent the templated formation of $\alpha$-synuclein inclusions.

\section{Materials and Methods}

Unless otherwise noted, all materials were purchased from Fisher Scientific.

\section{Animals}

All animal protocols were approved by our University's Institutional Animal Care and Use Committee. Mice were on a 12/12 h light/dark cycle and had ad libitum access to food and water. Both male and female mice were used in this study. C57BL6/J mice were obtained from Jackson Labs. Tau wild-type, tau heterozygous, and tau knock-out mice were a generous gift from Erik Roberson, University of Alabama at Birmingham (full description in preparation). $\mathrm{Tau}^{\text {flox/flox }}$ mice contained loxP sites flanking exon 1, similar to the constitutive tau knock-out mice generated by deleting exon 1 (Dawson et al., 2001). The mice were crossed with flipase transgenic mice, which removed the neomycin cassette, then crossed to $\beta$-actin-Cre mice to generate the tau knock-out line. The mice were created in C57BL/6 ES cells and maintained on a congenic C57BL/ $6 \mathrm{~J}$ background.

\section{Preparation of fibrils}

Fibrils were generated as described previously (Stoyka et al., 2020). Mouse $\alpha$-synuclein was purified in Escherichia 
coli using a Pierce LAL high-capacity endotoxin removal resin to minimize endotoxin. The concentration of monomeric $\alpha$-synuclein was measured by absorbance at $280 \mathrm{~nm}$ with an extinction coefficient of $7450 \mathrm{M}^{-1} \mathrm{~cm}^{-1}$. Fibrils were generated by incubating monomeric $\alpha$-synuclein $(300 \mu \mathrm{m})$ in $150 \mathrm{~mm} \mathrm{KCl}, 50 \mathrm{~mm}$ Tris- $\mathrm{HCl}$ at $37^{\circ} \mathrm{C}$ with constant agitation for $7 d$ (Bousset et al., 2013). After the seventh day, fibrils were isolated from remaining monomer by centrifugation for $10 \mathrm{~min}$ at 13,200 rpm and resuspended in half the initial volume of buffer. Five $\mu \mathrm{l}$ of fibrils were incubated for one hour with $8 \mathrm{~m}$ guanidinium chloride to dissociate the fibrils into monomer, the concentration of $\alpha$-synuclein was measured, and remaining fibrils were diluted to a final concentration of $300 \mu \mathrm{m} ; 22 \mu \mathrm{l}$ aliquots were stored at $-80^{\circ} \mathrm{C}$. On the day of injection, the fibril aliquots were thawed and sonicated using a Qsonica 700 W cup horn sonicator system at $80 \%$ amplitude for two rounds of $15 \mathrm{~min}$ sonication at $3 \mathrm{~s}$ on/2 s off, held at $15^{\circ} \mathrm{C}$ for a total sonication time of $30 \mathrm{~min}$. After 15 min of sonication, droplets on tube walls were gently scraped down into solution using a pipette tip. Size of sonicated fibrils was measured to ensure proper sonication using dynamic light scattering on a DynaPro NanoStar Dynamic Light Scattering Detector (Wyatt Technology). Although this method is optimized for round particles and only approximates the sonicated fibrils, this method ensures sufficient fragmentation of the fibrils (Froula et al., 2019), which is essential for the fibril model to induce sufficient formation of $\alpha$-synuclein inclusions. The average size of sonicated fibrils was under $60 \mathrm{~nm}$. Sonicated fibrils were kept at room temperature during injections. We have found the fibril fragments generated using this procedure remain stable for at least $3 \mathrm{~d}$ at room temperature. Before injection of monomeric $\alpha$-synuclein, protein was thawed on ice, spun at $20,000 \times g$ at $4^{\circ} \mathrm{C}$, and kept on ice until injected.

\section{Primary neuron cultures}

Neurons were prepared as described previously (VolpicelliDaley et al., 2014a,b). For all experiments, heterozygous mice for the tau knock-out gene were bred to give littermate pups of all three genotypes. Upon dissection, tail clippings were taken to confirm genotype of pups. Briefly, cortices were dissected from embryonic [embryonic day (E)16-E18] mice in Hibernate E, digested with papain in HBSS with $10 \mathrm{~mm}$ HEPES, $1 \mathrm{~mm}$ sodium pyruvate, and $1 \%$ penicillin/streptomycin, then titrated and plated in Neurobasal media (Invitrogen) with B27 (Invitrogen), GlutaMAX (Invitrogen), penicillin/streptomycin, and 10\% fetal bovine serum. Twelve hours later, the media was changed to Neurobasal/B27/GlutaMAX without fetal bovine serum or penicillin/streptomycin. Neurons were plated at a density of $5 \times 10^{5}$ cells per plate for $35-\mathrm{mm}$ dishes or $1 \times 10^{5}$ cells per coverslip.

\section{Proximity ligation assay (PLA)}

Association between tau and $\alpha$-synuclein was examined using PLA (DuoLink PLA kit, Sigma) with an anti-mouse PLA probe plus and anti-rabbit PLA probe minus. Primary antibodies were monoclonal mouse antibody to the C-terminal of $\alpha$-synuclein (SYN202, BioLegend, RRID: AB_2734606) and rabbit polyclonal antibody to the microtubule binding domain of tau (A0024, Dako, AB_10013724). DuoLink kit was used according to the manufacturer's instructions. Briefly, cortical cultures at day in vitro (DIV) 7-DIV10 were fixed for $30 \mathrm{~min}$ in $4 \%$ paraformaldehyde (PFA)/4\% sucrose in PBS and permeabilized, then blocked in 5\% normal goat serum in PBS and incubated with primary antibodies overnight at $4^{\circ} \mathrm{C}$. After three rinses, coverslips were incubated with PLA probes in a humidified chamber for $1 \mathrm{~h}$ at $37^{\circ} \mathrm{C}$. Probes were then ligated and amplified using included polymerase, ligase, and diluents. Supplied wash buffers were used according to manufacturer's recommendation, and coverslips were mounted with supplied Duolink mounting medium. Provided mounting medium contained DAPI and coverslips were sealed using clear nail polish.

\section{Expansion microscopy}

Expansion microscopy was performed as described (Chen et al., 2015; Asano et al., 2018; Wassie et al., 2019). Three-month-old C57BL/6 mice were transcardially perfused with $2 \%$ acrylamide in PBS followed by $4 \%$ PFA $30 \%$ acrylamide in PBS. Brains were then postfixed in the $4 \% \mathrm{PFA} / 30 \%$ acrylamide solution for $12 \mathrm{~h}$ and then stored in PBS at $4^{\circ} \mathrm{C}$. Brains were sectioned coronally at $50-\mu \mathrm{m}$ thickness on a Leica VT1000S vibratome. Sections were incubated for $30 \mathrm{~min}$ at $4^{\circ} \mathrm{C}$ in gelling solution of $86.6 \%$ monomer solution (prepared on ice, $0.38 \mathrm{~g} / \mathrm{ml}$ sodium acrylate, Sigma; $0.5 \mathrm{~g} / \mathrm{ml}$ acrylamide, Sigma; $0.29 \mathrm{~g} / \mathrm{ml}$ $\mathrm{NaCl} ; 1 \times \mathrm{PBS}), 7.4 \%$ crosslinker solution $\left(0.2 \mathrm{~g} / \mathrm{ml} \mathrm{N}, \mathrm{N}^{\prime}-\right.$ methylenebisacrylamide, Sigma), 2\% initiator solution (10\% ammonium persulfate), $2 \%$ accelerator solution (10\% tetramethylethylenediamine), $2 \%$ inhibitor solution (0.5\% 4-hydroxy-TEMPO). Sections were then incubated for a further $2 \mathrm{~h}$ at $37^{\circ} \mathrm{C}$, which initiated polymerization of the gel. Sections were trimmed to regions of interest and denatured using a solution of $200 \mathrm{~mm}$ SDS, $200 \mathrm{~mm} \mathrm{NaCl}, 40 \mathrm{~mm}$ Tris, $\mathrm{pH} 9$ for $1 \mathrm{~h}$ at $37^{\circ} \mathrm{C}$ and $1 \mathrm{~h}$ at $95^{\circ} \mathrm{C}$. Denaturation removed PFA-induced crosslinking and ensures equal expansion of biomolecules.

Following denaturation, samples were rinsed with $5 \times$ with PBS, 20 min each with gentle agitation at room temperature. Samples were blocked $2 \mathrm{~h}$ at room temperature with agitation, and incubated with primary antibodies at $0.001 \mathrm{mg} / \mathrm{ml}$ in blocking solution $(5 \%$ normal goat serum/ $0.1 \%$ Triton $\mathrm{X}-100$ in $1 \times \mathrm{PBS}$ ) for $48 \mathrm{~h}$ at $4^{\circ} \mathrm{C}$. Antibodies included SYN202 (BioLegend, RRID: AB_2734606) and tau (A0024, Dako, AB_10013724), and VAMP2 (Synaptic Systems, RRID: AB_2619758). After primary antibody incubation, samples were rinsed $5 \times, 1 \mathrm{~h}$, in $1 \times \mathrm{PBS}$ at $4^{\circ} \mathrm{C}$ with constant agitation. This was followed by an overnight incubation at $4^{\circ} \mathrm{C}$ with secondary antibody at $0.004 \mathrm{mg} / \mathrm{ml}$ in blocking solution. Finally, samples were rinsed in PBS, $1 \mathrm{~h}$ each, followed by three 20 -min washes in DI water to reach full expansion size $(\sim 6 \times$ initial size). Imaging was performed immediately on completion of expansion; imaging was completed using a $40 \times$ water-immersion objective (Nikon CFI Apo $\lambda$ S objective; MRD77410) on an inverted Nikon A1 SIM confocal microscope. 


\section{Immunoblotting}

At three months of age, tau mice were anesthetized using isoflurane and transcardially perfused using $0.9 \%$ saline, $10 \mathrm{U} / \mathrm{ml}$ heparin, and $0.5 \% \mathrm{w} / \mathrm{v}$ sodium nitroprusside. Brains were removed and the midbrain and forebrain were isolated. Using fine forceps, the midbrain and forebrain were dissected into distinct brain regions consisting of the cortex, striatum, hippocampus, and midbrain, which were flash frozen using liquid nitrogen and stored at $-80^{\circ} \mathrm{C}$. Samples were processed for Western blotting using $0.1 \%$ Triton X-100 in TBS and mechanical homogenization using a motorized tissue grinder. After lysing, samples were centrifuged for $10 \mathrm{~min}$ at $4^{\circ} \mathrm{C} 1000 \times \mathrm{g}$. The supernatant was diluted into Laemmli buffer with $5 \%$ fresh dithiothreitol (DTT) added. Samples were boiled for $5 \mathrm{~min}$ and resolved on 4-20\% gradient Mini-PROTEAN TGX Precast Protein Gels (Bio-Rad) and transferred to PVDF membrane (Millipore). The membrane was fixed using $0.4 \%$ PFA in PBS for 30 min and washed 3 times in TBS/Tween (TBST; $25 \mathrm{~mm}$ Tris- $\mathrm{HCl}, 137 \mathrm{~mm} \mathrm{NaCl}$, and $0.1 \%$ Tween 20). Blots were blocked using $5 \%$ non-fat dry milk in TBST for $1 \mathrm{~h}$ at room temperature and then incubated at $4^{\circ} \mathrm{C}$ overnight with primary antibodies to mouse monoclonal Tau46 (Cell Signaling, AB_10695394), mouse monoclonal vinculin (Bio-Rad, AB_2214389), or rabbit monoclonal $\alpha$-synuclein (AbCam, AB_869971) in blocking solution. After incubation, blots were washed three times with TBST and further incubated for $2 \mathrm{~h}$ at room temperature in IgG $\mathrm{H}+\mathrm{L}$ Cross-Absorbed Goat antimouse HRP (Invitrogen) or IgG H + L Cross-Absorbed donkey anti-rabbit HRP (Invitrogen) blocking solution. Following three rinses with TBST, blots were incubated in enhanced chemiluminescence Western Blotting Substrate (Thermofisher) for $1 \mathrm{~min}$ at room temperature and developed using ChemiDoc Touch Imaging System (Bio-Rad).

\section{Intrastriatal injection of recombinant $\alpha$-synuclein fibrils}

At three to four months of age, male and female tau wild-type, heterozygous, and knock-out mice were deeply anesthetized with vaporized isoflurane on a stereotactic frame. Mice were then injected with $2 \mu \mathrm{l}$ (per side) of 300 $\mu \mathrm{m}$ sonicated fibrils or $300 \mu \mathrm{m}$ monomeric $\alpha$-synuclein (as control) bilaterally into the striatum. The coordinates for the striatum were $+1.0 \mathrm{~mm} \mathrm{AP}, \pm 2.0 \mathrm{~mm} \mathrm{ML},-26 \mathrm{~mm}$ DV. Solutions were injected at a constant rate of $0.5 \mu \mathrm{L} /$ min; once injection was complete, the needle was left in place for $5 \mathrm{~min}$ and then slowly withdrawn. Between 9 and 10 mice per group were used, resulting in a total of 56 mice used for the study.

\section{Behavior testing}

Behavior tests to assess motor and non-motor function were conducted either 1.5 or six months after injection as described previously (Stoyka et al., 2020). One week before testing began, mice were transported to the behavior core; mice were handled for $3 \mathrm{~d}$ before testing began. Additionally, mice were habituated to the testing room for one hour at the onset of each testing day. All mice underwent open field test, followed by fear conditioning. Mice had 1-3 d of rest between testing paradigms. The researcher conducting and analyzing the test was blinded to treatment and genotype. All apparatuses were cleaned with $70 \%$ ethanol or $2 \%$ chlorhexidine between trials.

\section{Open field test}

Mice were placed in an open field apparatus that was $43 \times 43 \mathrm{~cm}$ with $30-\mathrm{cm}$-high walls. To prevent bias from external factors, the walls were opaque such that mice could not view the external environment and a white noise generator was turned on for the entirety of the testing day. The lighting in the room was the overhead fluorescent lights. Mice were allowed to explore for $10 \mathrm{~min}$. Velocity, mobility, and percent time in center were recorded by Med Associates Activity Monitor.

\section{Fear conditioning}

Mice were placed in a novel environment and trained to associate a tone (conditioned stimulus; CS) with a mild foot shock (unconditioned stimulus, US). After 2 min in the novel environment, a continuous tone would play for $30 \mathrm{~s}$, culminating in a $0.8 \mathrm{~mA}, 2-\mathrm{s}$ foot shock. Thirty seconds later, the tone and shock would repeat; 1 min after the second shock, the training trial ended. Twenty-four hours later, mice were evaluated for contextual and cued fear conditioning. During contextual fear conditioning testing, mice were placed in the same environment as training, and freezing behavior was evaluated for $5 \mathrm{~min}$. Three hours later, mice were exposed to a novel environment (using novel scents, visual cues, and enclosure) and the CS is re-presented, this time without the foot shock. FreezeFrame software was used to record sessions. Freezing behavior during training, contextual, and cued fear conditioning was hand scored by a researcher blinded to treatment and genotype. Freezing behavior was defined as previously described (Stoyka et al., 2020).

\section{Immunohistochemistry and immunofluorescence}

At either 1.5 or six to seven months after injection of $\alpha$-synuclein fibrils or monomer, mice were anesthetized with isoflurane and transcardially perfused using $0.9 \%$ saline, $10 \mathrm{U} / \mathrm{ml}$ heparin, and $0.5 \% \mathrm{w} / \mathrm{v}$ sodium nitroprusside followed by cold $4 \%$ PFA in PBS. Brains were postfixed in $4 \%$ PFA in PBS for $16 \mathrm{~h}$ at $4{ }^{\circ} \mathrm{C}$, then switched to $30 \%$ sucrose in PBS for $24-48 \mathrm{~h}$ for cryoprotection. Samples were stored at $-80^{\circ} \mathrm{C}$ until serially sectioned at $40-\mu \mathrm{m}$ thickness on a freezing microtome, then stored at $-20^{\circ} \mathrm{C}$ in $50 \%$ glycerol, $0.01 \%$ sodium azide in tris-buffered saline (TBS). For immunohistochemistry, sections were rinsed four times in TBS and quenched in $3 \% \mathrm{H}_{2} \mathrm{O}_{2}$ in TBS for $10 \mathrm{~min}$. Following three rinses in TBS, sections were incubated in antigen retrieval solution $(10 \mathrm{~mm}$ sodium citrate, $0.05 \%$ Tween $20, \mathrm{pH}$ ) at $37^{\circ} \mathrm{C}$ for $1 \mathrm{~h}$, were rinsed three times in TBS, and blocked using $5 \%$ normal goat serum (Equitech-Bio Inc) with $0.1 \%$ Triton X-100 in TBS for $1 \mathrm{~h}$ at $4^{\circ} \mathrm{C}$. After blocking, sections were incubated in primary antibody solution of rabbit polyclonal antibody to tyrosine hydroxylase (TH; Sigma) in 5\% normal goat serum in TBS at $4^{\circ} \mathrm{C}$ overnight. After washes, sections were then incubated in Biotin-SP AffiniPure 
Donkey Anti-Rabbit IgG H\&L (Jackson ImmunoResearch) in $5 \%$ normal goat serum in TBS for $2 \mathrm{~h}$, followed by incubation with Avidin-Biotin Complex Peroxidase Standard Staining kit reagent for $1 \mathrm{~h}$ at room temperature. Sections were developed using ImmPACT-3 3'-diaminobenzidine (DAB; Vector Labs), sequentially dehydrated as clarified previously (Stoyka et al., 2020), and mounted on charged slides using Permount.

For immunofluorescence, sections underwent antigen retrieval, blocking, and primary antibody solutions as above. Primary antibodies were, SYN202 (BioLegend, RRID: AB_2734606) and tau (A0024, Dako, AB_10013724), and VAMP2 (Synaptic Systems, AB_2619758), or rabbit monoclonal to pSer129- $\alpha$-synuclein (AbCam, AB_869973). pSer129- $\alpha$-synuclein has been extensively characterized for staining mature Lewy-like aggregates (Delic et al., 2018). Following rinses, sections were incubated in appropriate Alexa Fluor-conjugated secondary antibodies (Invitrogen) diluted in blocking solution, rinsed and mounted on charged slides and coverslipped using Prolong Gold (Invitrogen).

\section{Fluorescent microscopy, aggregate analysis, and unbiased stereology}

Sections were imaged using a Zeiss Axiovert.Z1 microscope for wide-field fluorescence, Olympus BX51 microscope for bright field, or a Nikon C2 confocal microscope. Expanded sections were imaged on a Nikon A1 SIM confocal microscope. The researcher capturing images was blinded to genotype and treatment group.

For Lewy-like aggregate analysis, a single image of each side of the region of interest in fibril-injected mice [dorsomedial prefrontal cortex (dmPFC), basolateral amygdala, hippocampus, and $\mathrm{SNc}$ ] was captured at the approximate middle of the region rostral to caudal using the Nikon confocal microscope. For larger regions (PFC and hippocampus), a series of images were tiled together to create a "large field" image using Nikon Elements software. Care was taken to ensure representative images were matched across samples, with imaged sections at the following AP positions relative to bregma: $+2.0 \mathrm{~mm}$ for PFC, $-1.34 \mathrm{~mm}$ for basolateral amygdala, $-1.82 \mathrm{~mm}$ for hippocampus, and $-3.16 \mathrm{~mm}$ for SNc. As animals were injected bilaterally, right and left hemispheres were denoted, but both were quantified for all regions except the dmPFC. In the dmPFC, the hemispheres are not connected and therefore separated during coronal sectioning. As hemispheres could not be matched, only the left hemisphere was quantified. No differences between hemispheres were noted in any region. A researcher blinded to genotype outlined the region of interest and quantified Lewy-like aggregates using Fiji CellCounter. Both neuritic and somal aggregates were included during quantification. For analyses, hemispheres were evaluated separately, and then the average aggregate burden was binned for each sample.

Unbiased stereological analyses of TH neurons in the SNc were conducted using the Olympus BX51 bright field microscope, while using an optical fractionator probe (Stereo Investigator software, Stereology Resource
Center) as previously described (Harms et al., 2013). Briefly, four to five sections covering the SNc from rostral to caudal were quantified, representing a total of $960 \mu \mathrm{m}$. The optical dissector height was $22 \mu \mathrm{m}$, and the distance between the counting frame was $50 \mu \mathrm{m} \times 50 \mu \mathrm{m}$, with a section thickness of $33 \mu \mathrm{m}$. The counting variability was measured with the Schmitz-Hof coefficient of error (CE; Schmitz, 1998) and was 0.06 .

\section{Statistical analyses}

Statistical analyses were performed using GraphPad Prism. Data are presented as mean \pm SEM. Data were first tested for normality using the Shapiro-Wilk normality test. Normally distributed data were analyzed using an independent, unpaired $t$ tests (for two groups), one-way or two-way ANOVA. Data that did not fit a normal distribution were analyzed using a Kruskal-Wallis test (for three groups; Table 1).

\section{Results}

\section{Tau and $\alpha$-synuclein interact in primary cortical neurons}

PLA localizes protein-protein interactions (Söderberg et al., 2008; Pelayo et al., 2011) via oligonucleotides bound to secondary antibodies. $\alpha$-Synuclein-tau interactions were examined in mature (14 DIV) primary cortical neuronal cultures from tau wild-type, heterozygous, and knockout mice. Antibodies to the $\mathrm{C}$ terminus of $\alpha$-synuclein and the microtubule binding domain of tau were used because these two domains interact in vitro (Dasari et al., 2019). In the absence of tau, there was no fluorescence, indicating that the PLA secondary antibodies and oligonucleotides do not nonspecifically bind to the neurons and produce fluorescence. Conversely, tau wild-type and heterozygous cultures showed high levels of fluorescence, indicating association of tau and $\alpha$-synuclein (Fig. 1A). Primary neurons from tau heterozygous mice showed significantly less $(\sim 30 \%)$ fluorescence than those from wild-type animals, indicating that a reduction in tau decreases the pool of tau interacting with $\alpha$-synuclein.

\section{Reducing tau does not prevent $\alpha$-synuclein inclusion formation}

To examine the impact of reducing tau on fibril-induced $\alpha$-synuclein inclusion formation, fibrils generated from recombinant $\alpha$-synuclein were added to neurons from wildtype, tau heterozygous, or tau knock-out mice. The formation of inclusions, identified using an antibody to $\mathrm{p}$ $\alpha$-synuclein, was quantified using immunofluorescence and confocal microscopy. The abundance of $\alpha$-synuclein inclusions was not reduced in neurons from either tau heterozygous mice or tau knock-out mice compared with wild-type mice (Fig. 1B). Overall, reducing tau did not inhibit fibril-induced $\alpha$-synuclein inclusion formation in primary cortical neurons.

$\alpha$-Synuclein expression and fibril-induced $\alpha$-synuclein inclusion formation depends on synapse formation (Murphy et al., 2000; Volpicelli-Daley et al., 2011), which may be impaired by reducing tau (Dawson et al., 
Table 1: Statistical table describing the figure, data, type of test and statistics results

\begin{tabular}{ll}
\hline Figure & Graph identification \\
\hline Fig. 1A & \\
Fig. 1B & DIV10 \\
Fig. 1C & DIV18 \\
& \\
& \\
Fig. 2C & Cortex, tau \\
& Cortex, synuclein \\
& Striatum, tau \\
& Striatum, synuclein \\
& Hippocampus, tau \\
& Hippocampus, synuclein \\
& Midbrain, tau \\
& Midbrain, synuclein \\
& PFC \\
Fig. $3 B$ & Basolateral amygdala \\
& Dentate gyrus \\
& CA1-CA3 \\
& SNc
\end{tabular}

Fig. $4 B$

Fig. $5 A$

Velocity

Distance

Percent time in center

Fig. $5 B \quad$ Training

Contextual

Cued

Fig. $6 B$

Fig. 6C

PFC

Basolateral amygdala Hippocampus

SNC

Velocity

Distance

Percent time in center

Fig. $6 D$

Training

Contextual

Cued

Extended Data Fig. 1-1

Extended Data Fig. 1-2A

Extended Data Fig. 3-1
Type of test Statistics

Kruskal-Wallis test $H_{(2)}=120.6, p<0.0001$

One-way ANOVA $\quad F_{(2,6)}=1.1, p=0.39$

Two-way ANOVA Interaction: $F_{(2,263)}=1.360, p=0.2584$

Two-way ANOVA

Interaction: $F_{(2,237)}=6.956, p=0.0012$; treatment:

$F_{(1,237)}=16.61, p<0.0001$; genotype: $F_{(2,237)}=44.00$, $p<0.0001$

One-way ANOVA $\quad F_{(2,6)}=151.0, p<0.0001$

One-way ANOVA $\quad F_{(2,6)}=2.703, p=0.1455$

One-way ANOVA $\quad F_{(2,6)}=110.5, p<0.0001$

One-way ANOVA $\quad F_{(2,6)}=3.611, p=0.0934$

One-way ANOVA $\quad F_{(2,6)}=73.06, p<0.0001$

One-way ANOVA $\quad F_{(2,6)}=0.112, p=0.8958$

One-way ANOVA $\quad F_{(2,6)}=152.1, p<0.0001$

One-way ANOVA $\quad F_{(2,6)}=0.1251, p=0.8846$

One-way ANOVA $\quad F_{(2,24)}=0.2523, p=0.7791$

One-way ANOVA $\quad F_{(2,25)}=1.368, p=0.2731$

Kruskal-Wallis test $H=1.161, p=0.3223$

Kruskal-Wallis test $H=2.265, p=0.5597$

One-way ANOVA $\quad F_{(2,24)}=2.119, p=0.1421$

Two-way ANOVA Interaction: $F_{(2,38)}=0.5941, p=0.5571$; treatment: $F_{(1,38)}=$ $61.12, p<0.0001$; genotype: $F_{(2,38)}=0.1630, p=0.8502$.

Two-way ANOVA One outlier removed interaction: $F_{(2,48)}=2.700, p=0.0774$; treatment: $F_{(1,48)}=3.248, p=0.0778$; genotype: $F_{(2,248)}=$ $2.805, p=0.0705$.

Two-way ANOVA Interaction: $F_{(2,49)}=4.9, p=0.01$; treatment: $F_{(1,49)}=0.79$, $p=0.38$; genotype: $F_{(2,49)}=3.7, p=0.03$

Two-way ANOVA Interaction: $F_{(2,49)}=0.7311, p=0.4866$; treatment: $F_{(1,49)}=$ $0.1434, p=0.7066$; genotype: $F_{(2,49)}=0.7588, p=0.4736$

Three-way ANOVA Three-way interaction: $F_{(8,170)}=0.64, p=0.7449$; genotype $\times$ treatment: $F_{(2,170)}=0.9, p=0.4075$; genotype $\times$ time: $F_{(8,170)}=0.54, p=0.8246$; treatment $\times$ time: $F_{(4,170)}=$ $0.16, p=0.9583$; treatment: $F_{(1,170)}=0.76, p=0.385$; genotype: $F_{(2,170)}=7.44, p=0.0008$; time: $F_{(4,170)}=21.57$, $p<0.0001$

Two-way ANOVA Interaction: $F_{(2,46)}=0.7843, p=0.4624$; treatment: $F_{(1,46)}=$ $0.003584, p=0.9525$; genotype: $F_{(2,46)}=1.826, p=0.1725$

Two-way ANOVA Interaction: $F_{(2,49)}=4.003, p=0.0245$; treatment: $F_{(1,49)}=$ $1.171, p=0.2844$; genotype: $F_{(2,49)}=3.907, p=0.0266$

Independent $t$ test $t_{(14)}=1.8, p=0.09$

Independent $t$ test $t_{(14)}=1.02, p=0.32$

Independent $t$ test $t_{(13)}=0.65, p=0.52$

Independent $t$ test $t_{(14)}=0.53, p=0.6$

Two-way ANOVA Interaction: $F_{(1,27)}=3.1, p=0.09$; treatment: $F_{(1,27)}=0.5$, $p=0.5$; genotype: $F_{(1,27)}=1.4, p=0.24$

Two-way ANOVA Interaction: $F_{(1,27)}=0.13, p=0.71$; treatment: $F_{(1,27)}=0.47$, $p=0.49$; genotype: $F_{(1,27)}=0.2, p=0.65$

Two-way ANOVA Interaction: $F_{(1,27)}=1.5, p=0.23$; treatment: $F_{(1,27)}=1.3$, $p=0.26$; genotype: $F_{(1,2)}=0.12, p=0.72$

Three-way ANOVA Interaction: $F_{(16,120)}=0.8, p=0.67$; genotype $\times$ treatment: $F_{(4,30)}=0.5, p=0.71$; time: $F_{(2,88)}=42.8, p<0.0001$

Two-way ANOVA Interaction: $F_{(1,29)}=1.4, p=0.23$; treatment: $F_{(1,27)}=0.43$, $p=0.51$; genotype: $F_{(1,29)}=2.8, p=0.11$

Two-way ANOVA Interaction: $F_{(1,27)}=17.52, p=0.0003$; treatment: $F_{(1,27)}=$ 4.5, $p=0.04$; genotype: $F_{(1,27)}=3.9, p=0.05$

Kruskal-Wallis test $H=0.6935, p=0.7070$

Two-way ANOVA Interaction: $F_{(2,268)}=7.2, p=0.0009$; treatment: $F_{(1,268)}=$ $22.1, p<0.0001$; genotype: $F_{(2,268)}=1.678, p=0.1886$.

One-way ANOVA $\quad F_{(2,21)}=0.4911, p=0.618$
2001). Thus, we measured the colocalization of presynaptic vGLUT1 and postsynaptic Homer to determine whether reducing tau inhibits synapse formation. We also examined whether adding fibrils reduced synapses, by adding $\alpha$-synuclein fibrils at DIV7 and measuring overlap of vGLUT1 and Homer (Fig. 1C,D). Synapses begin to mature by DIV10 (Fletcher et al., 1994). At this time point, there were no significant 
A

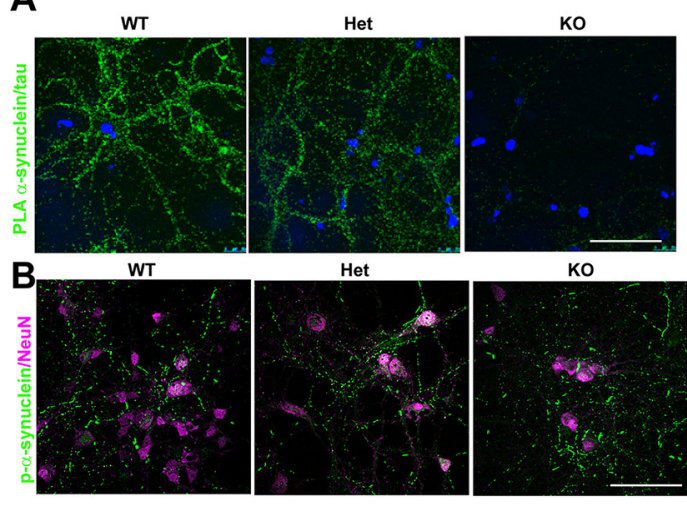

D

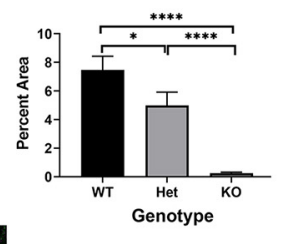

DIV18

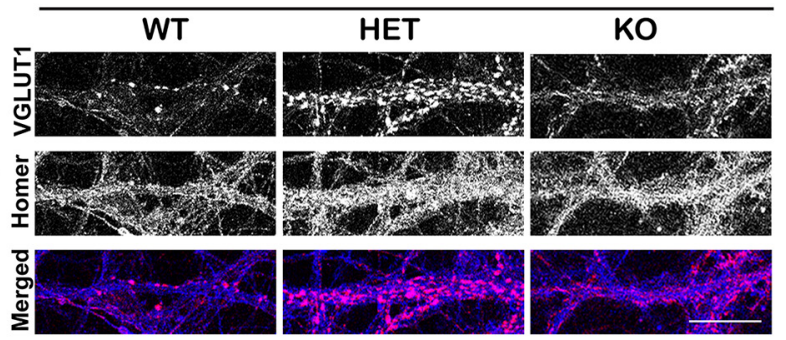

Fibril

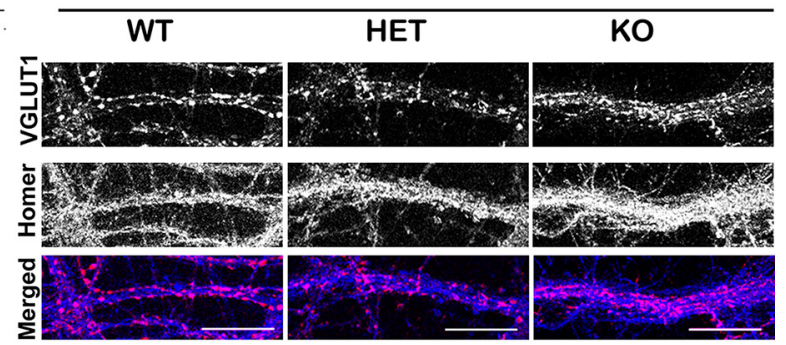

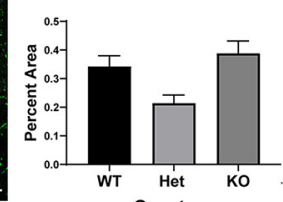

Fibril
C

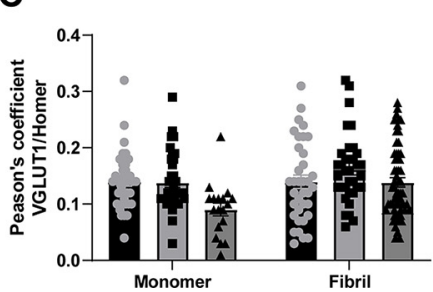

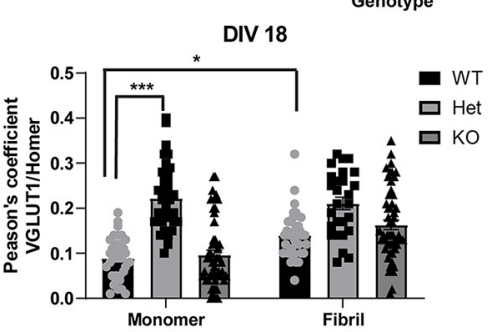

Figure 1. A, Primary cortical neurons at DIV14 from wild-type, tau heterozygous mice, or tau knock-out mice were fixed and labeled with antibodies to the $\mathrm{C}$ terminus of $\alpha$-synuclein and the microtubule binding domain of tau. PLA was performed to detect an interaction between the two proteins. Images of 10 fields for each condition were captured using confocal microscopy. The percent area occupied by fluorescent signal was quantified using Fiji. The experiment was performed three times and data were analyzed with a Kruskal-Wallis test $H_{(2)}=120, p<0.0001$. Scale bar: $50 \mu \mathrm{m}$. B . Primary cortical neurons were exposed to monomeric $\alpha$-synuclein or $\alpha$-synuclein fibrils $1 \mu \mathrm{g} / \mathrm{mL}$ at DIV7 from wild-type, tau heterozygous mice, or tau knock-out mice. Seven days later, neurons were fixed and labeled with antibodies to $\mathrm{p}$ - $\alpha$-synuclein or NeuN to identify neuronal nuclei. The percent area occupied by fluorescent signal was quantified using Fiji. The experiment was performed three times. One-way ANOVA $F_{(2,6)}=1.1, p=0.39,{ }^{*} p<0.05$, ${ }^{* \star *} p<0.001,{ }^{* * \star *} p<0.0001$. C, Primary cortical neurons were exposed to monomeric $\alpha$-synuclein or $\alpha$-synuclein fibrils at DIV7 from wild-type, tau heterozygous mice, or tau knock-out mice. Three days later or eleven days later, neurons were fixed and labeled with antibodies to presynaptic vGLUT1, or postsynaptic Homer. Pearson's coefficient measuring the percent overlap of vGLUT1 over Homer was quantified using Fiji. For DIV10 $F_{(2,263)}=1.36, p=0.26$. For DIV18 Two way ANOVA interaction $F_{(2,237)}=6.546$. Two-way ANOVA. Interaction: $F_{(2,237)}=6.596, p=0.0012$; treatment: $F_{(1,237)}=16.61, p<0.0001$; genotype: $F_{(2,237)}=44.0$, p $<0.0001$. Scale bar: $50 \mu \mathrm{m}$. $\boldsymbol{D}$, Representative images of labeled with antibodies to presynaptic vGLUT1 (magenta in merged image) or postsynaptic Homer (blue in merged image). Images were captured using confocal microscopy. Scale bar: $25 \mu \mathrm{m}$. Extended Data Figure 1-1 shows data from an internalization assay of Alexa Fluor 488-labeled fibrils demonstrated no difference in uptake of fibrils among genotypes. Extended Data Figure 1-2 shows data from a DQ-BSA assay demonstrating that neurons from tau heterozygous mice exposed to fibrils have increased lysosome activity compared neurons exposed to $\alpha$-synuclein monomer.

differences in the overlap of vGLUT1 and Homer in neurons with reduced tau, or neurons $3 \mathrm{~d}$ following exposure to fibrils. At DIV18, however, tau heterozygous neurons (but not tau knock-out neurons) showed increased overlap of vGLUT1 and Homer (Fig. 1C,D). vGLUT1 immunofluorescence in particular appeared brighter with larger puncta, suggesting that reducing tau by $50 \%$ enhances synapse formation. Overall, the data showed that reducing tau does not inhibit synapse formation. In wild-type neurons, addition of fibrils also increased overlap of vGLUT1 and Homer with vGLUT1 puncta appearing brighter and larger, consistent with findings of increased volume of presynaptic terminals in the cortex and striatum in DLB cases (Colom-Cadena et al., 2017). We also determined whether tau reduction impairs fibril internalization. Neither neurons from tau heterozygous mice nor tau knock-out mice showed alterations in the internalization of Alexa Fluor 488-labeled $\alpha$-synuclein fibrils compared with neurons from wild-type controls (Extended Data Fig. 1-1) (Karpowicz et al., 2017). Because turnover of $\alpha$-synuclein could also impact aggregation, lysosome activity was also measured using a DQ-BSA, which fluoresces when cleaved by lysosomal proteases. Addition of fibrils significantly increased the abundance of active lysosomes in the tau heterozygous primary neurons at $7 \mathrm{~d}$ after adding fibrils, compared with neurons exposed to monomer (Extended Data Fig. 1-2).

\section{Tau partially overlaps with $\alpha$-synuclein at excitatory synapses}

$\alpha$-Synuclein concentrates at the presynaptic terminal, particularly in excitatory neurons in the cortex (Taguchi et al., 2016). Tau localizes to the axon and plays a role in synaptic vesicle endo/exocytosis at the presynaptic terminal (Zhou et al., 2017; Mclnnes et al., 2018). Tau expression is also enriched in excitatory neurons in the 
A
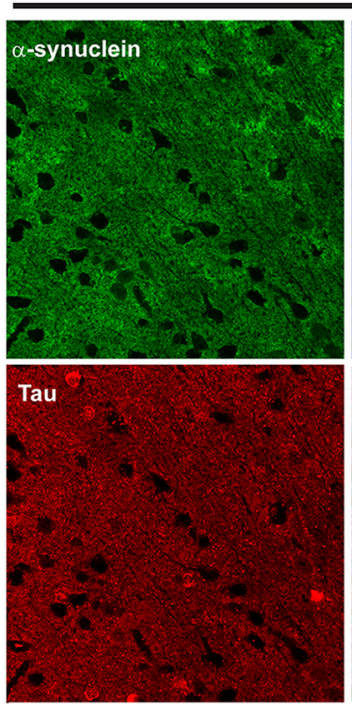

B
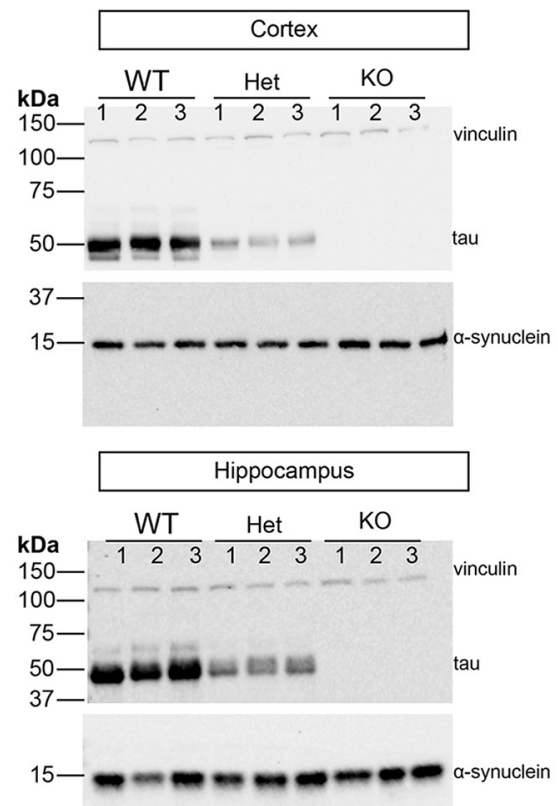
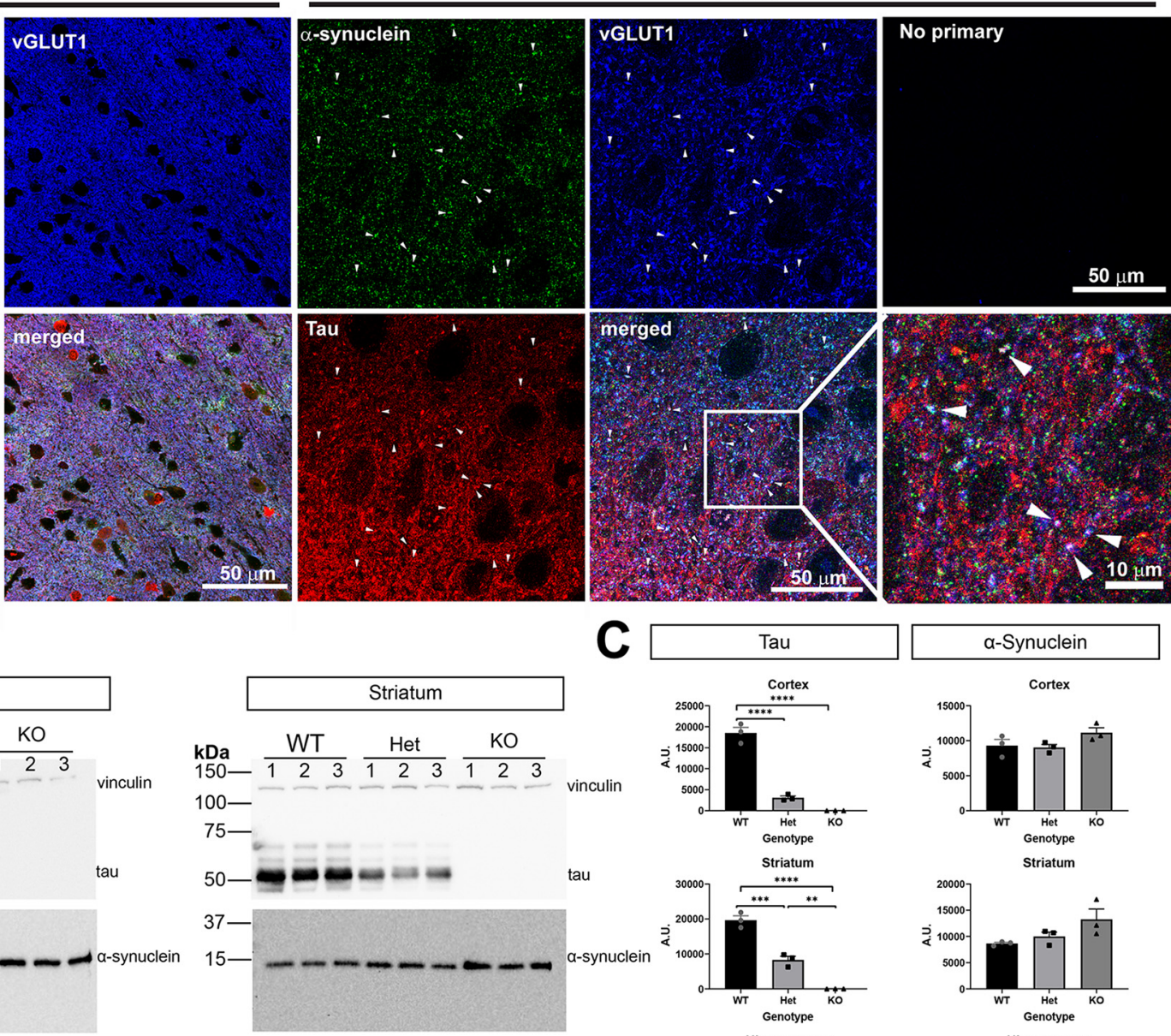

tau
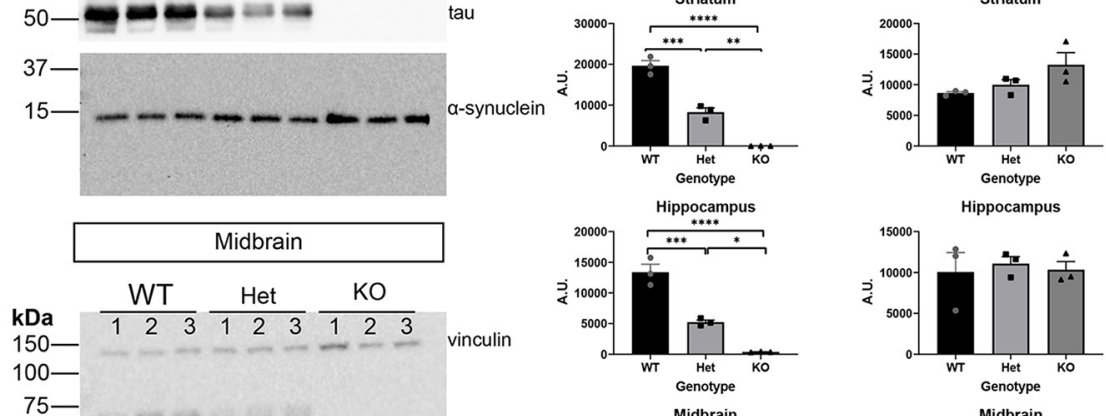

Hippocampus
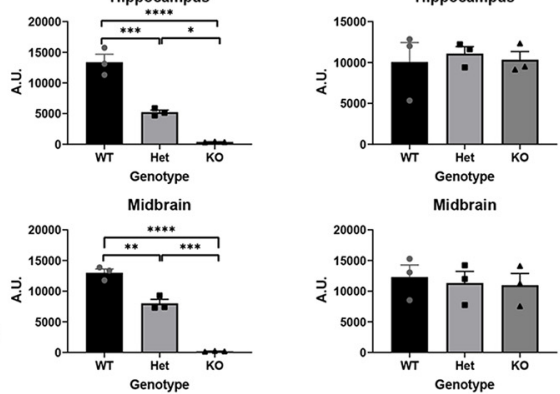

Figure 2. $\boldsymbol{A}$, Cortical mouse section with immunofluorescence using antibodies to tau, $\alpha$-synuclein, and vGLUT1. Images were scanned using confocal microscopy. Scale bar: $50 \mu \mathrm{m}$. B. Expansion microscopy (2x expansion) was performed along with antibodies as in $\boldsymbol{A}$. Images capture using confocal microscopy. Arrowheads point to puncta in which tau, $\alpha$-synuclein, and vGLUT1 overlap. The top right panel shows a confocal image from expanded sections in which no primary antibodies were included but all three secondary antibodies were included. The bottom right panel shows a higher magnification image from the panel to the left. Scale bar: 10 or $50 \mu \mathrm{m}$ as indicated. C, Immunoblots from cortex, striatum, hippocampus homogenates of three-month-old tau wild-type, heterozygous, and knock-out mice. Vinculin was used as a loading control. $\boldsymbol{D}$, Quantification of immunoblots was performed using Fiji. One-way ANOVA. Cortex (tau $F_{(2,6)}=151.0, p<0.0001$; synuclein $\left.F_{(2,6)}=2.703, p=0.1455\right)$. Striatum (tau $F_{(2,6)}=110.5, p<0.0001$; synuclein $F_{(2,6)}=3.611, p=0.0934$ ). Hippocampus (tau $F_{(2,6)}=73.06, p<0.0001$; synuclein $F_{(2,6)}=0.112, p=0.8958$ ). Midbrain (tau $F_{(2,6)}=152.1, p<0.0001$; synuclein $\left.F_{(2,6)}=0.1251, p=0.8846\right) ;{ }^{*} p<0.05,{ }^{* *} p<0.01,{ }^{* *} p<0.005,{ }^{* * *} p<0.0001 . N=3$ independent mice.

cortex (Fu et al., 2019). We first examined localization of $\alpha$-synuclein and tau in cortical sections of wild-type mice. Using indirect immunofluorescence and traditional confocal microscopy, $\alpha$-synuclein, tau, and vGLUT1, a presynaptic excitatory neuron marker, appeared diffuse throughout the neuropil of the cortex (Fig. 2A). To increase our resolution, we used expansion microscopy, which utilizes a polymer matrix to mechanically expand tissue 
A
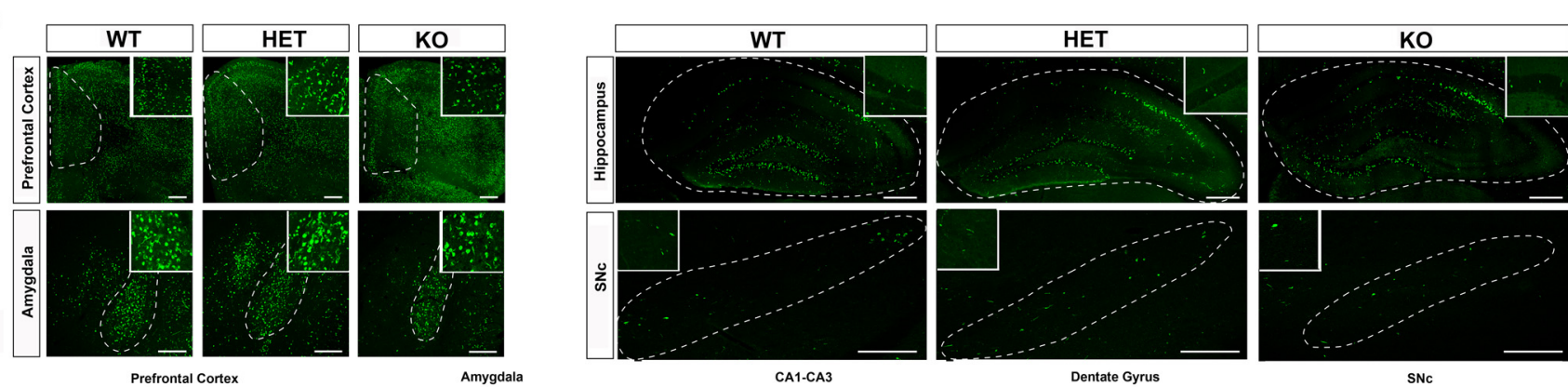

B
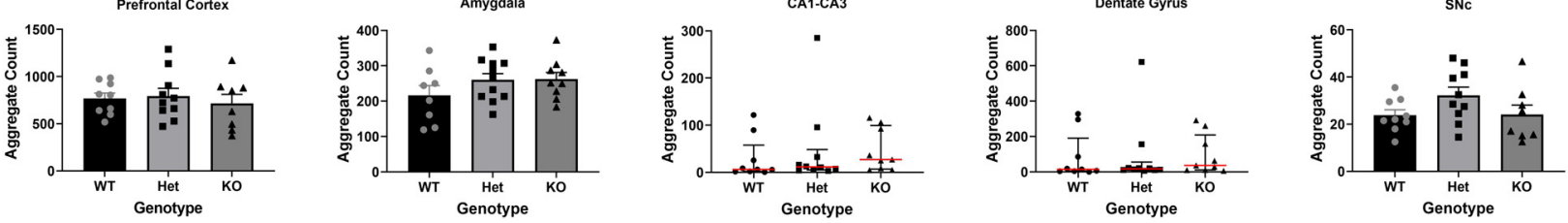

Figure 3. $\boldsymbol{A}$, Six months after bilateral striatal injection of $\alpha$-synuclein fibrils, mice were perfused and immunofluorescence to p$\alpha$-synuclein was performed. Images were captured using confocal microscopy and $\mathrm{p}$ - $\alpha$-inclusions were quantified using Fiji. Higher magnification inserts are provided for visualization of inclusions. B, Quantification of PFC (left), basolateral amygdala (center left), dentate gyrus of the hippocampus (center), CA1-CA3 of the hippocampus (center right) and SNc (right). PFC: one-way ANOVA, $F_{(2,24)}=0.2523, p=0.7791$. Basolateral amygdala: one-way ANOVA, $F_{(2,25)}=1.368, p=0.2731$. Dentate gyrus: Kruskal-Wallis test, $H=1.161, p=0.3223$. CA1-CA3: Kruskal-Wallis test, $H=2.265, p=0.5597$. SNc: one-way ANOVA, $F_{(2,24)}=2.119, p=0.1421 . N=8-$ 10/group. Scale bars: $250 \mu \mathrm{m}$. Extended Data Figure 3-1 shows data from unbiasaed stereology counts of $\alpha$-synuclein aggregates in the amygdala confirming no differences among fibril-injected wild-type, tau heterozygous, and tau knock-out mice.

evenly in 3 dimensions (Chen et al., 2015; Tillberg et al., 2016; Wassie et al., 2019). Using this technique along with traditional confocal microscopy, we expanded our cortical tissue sections. Distinct puncta corresponding to $\alpha$-synuclein and excitatory vGLUT1 presynaptic puncta were visible. A portion of tau immunofluorescence overlapped with $\alpha$-synuclein and vGLUT1, indicating that tau can localize to the presynaptic terminal along with $\alpha$-synuclein (Fig. 2A, bottom panels).

\section{Tau reduction does not affect $\alpha$-synuclein expression}

We determined whether tau reduction affects endogenous $\alpha$-synuclein levels in the brain, which could influence the extent of $\alpha$-synuclein aggregation. Homogenates of hippocampus, cortex, striatum, and midbrain were analyzed for levels of tau and $\alpha$-synuclein by immunoblot (Fig. 2B). As expected, tau heterozygous mice showed an $\sim 50 \%$ reduction of tau protein relative to wild-type littermates in all brain regions. Tau knock-out mice showed no tau expression. In all four brain regions analyzed, $\alpha$-synuclein levels were not significantly different regardless of tau expression (Fig. 2C). Although there appeared to be a trend toward an increase in $\alpha$-synuclein expression in the cortex and striatum, our data were not powered to detect a significant difference.

\section{Tau reduction does not prevent inclusion formation at six months after injection of $\alpha$-synuclein fibrils}

To evaluate the role of tau on Lewy-like aggregation, wild-type, heterozygous, and knock-out tau mice received bilateral injections of $\alpha$-synuclein fibrils or monomer at three to four months of age. Injection of $\alpha$-synuclein fibrils into the striatum induces Lewy-like aggregates in multiple brain regions important for LBDs (Luk et al., 2012; Froula et al., 2019; Stoyka et al., 2020), including the PFC, basolateral amygdala, striatum, and SNc. Monomeric $\alpha$-synuclein was injected as a control, which does not induce formation of $\alpha$-synuclein inclusions (Volpicelli-Daley et al., 2011; Froula et al., 2019). At six to seven months postinjection, mice were killed, and immunofluorescence was performed using an antibody to $\alpha$-synuclein phosphorylated at Ser129 (p-a-syn) to identify inclusions (Fig. 3). In both humans and in murine models, $\alpha$-synuclein is hyperphosphorylated in aggregates (Fujiwara et al., 2002), this antibody recognizes Lewy aggregates in PD and DLB brains (Fujiwara et al., 2002). The PFC and basolateral amygdala contained heavy burdens of Lewy-like aggregates, consistent with previous observations (Luk et al., 2012; Froula et al., 2019; Sorrentino et al., 2019; Stoyka et al., 2020). The burden in the hippocampus was variable regardless of genotype. In general, the dentate gyrus had a higher burden than CA1-CA3, but the number of Lewy-like aggregates varied from few aggregates to hundreds. Compared with the other brain regions, the SNc had few aggregates, consistent with previous studies showing an increase in fibril induced $\alpha$-synuclein aggregates at three months postinjection followed by decreases at six months postinjection, likely because of concomitant death of aggregate-containing neurons (Abdelmotilib et al., 2017; Patterson et al., 2019). Indeed, tracking neurons in vivo has shown death following fibrilinduced aggregate formation (Osterberg et al., 2015). Quantification of aggregates revealed that the abundance of $\alpha$-synuclein inclusions was not significantly different in the cortex, amygdala, hippocampus, or SNc among wildtype, tau heterozygous, or tau knock-out mice (Fig. 3B). Unbiased stereology was also used to quantify aggregates in the basolateral amygdala, and confirmed that tau 

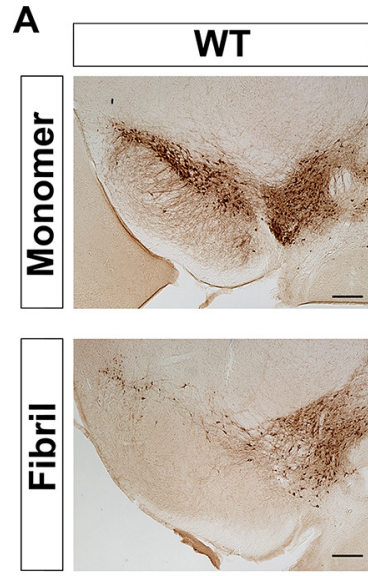
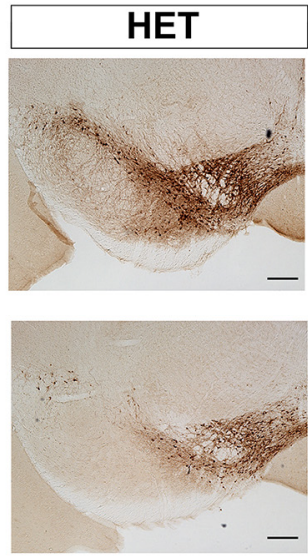
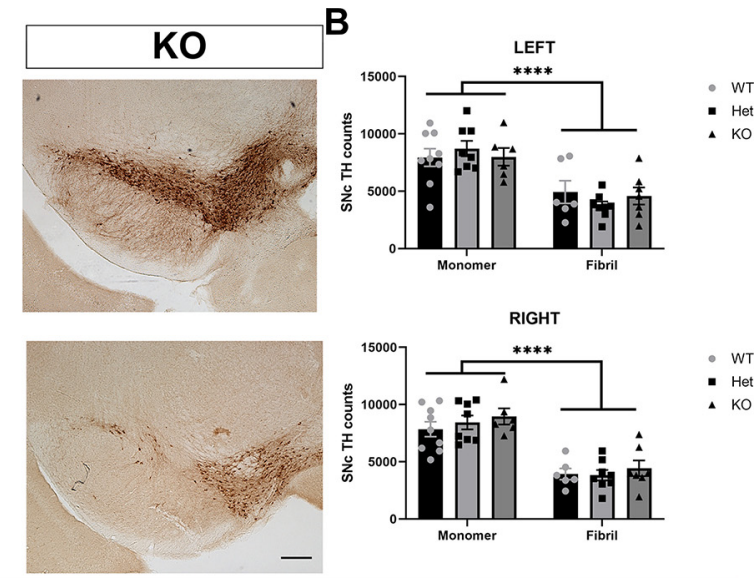

Figure 4. $\boldsymbol{A}$, Wild-type ( $N=9$, monomer; $N=6$, fibril), tau heterozygous ( $N=8$, monomer; $N=8$, fibril), or tau knock-out ( $N=6$, monomer; $N=7$, fibril) tau mice were perfused six months after injections. Immunohistochemistry was performed using an antibody to TH to identify dopamine neurons. $\boldsymbol{B}$, Unbiased stereology was performed to count TH-positive neurons in both the right and left SNc. The only significant difference was between monomer and fibril injection with no significant effect of genotype. Two-way ANOVA. Interaction: $F_{(2,38)}=0.5941, p=0.5571$; treatment: $F_{(1,38)}=61.12, p<0.0001$; genotype: $F_{(2,38)}=0.1630, p=0.8502 . N=6-8 /$ group; ${ }^{\star \star \star \star} p<0.0001$. Scale bar: $200 \mu \mathrm{m}$.

expression does not impact the abundance of fibril-induced inclusions (Extended Data Fig. 3-1).

\section{Tau reduction does not prevent loss of TH-positive neurons in the SNc at six months after injection of $\alpha$-synuclein fibrils}

To determine the effect of tau reduction on $\alpha$-synuclein inclusion-induced loss of dopamine neurons in the SNc, immunohistochemistry of serial sections of the midbrain was performed using an antibody to $\mathrm{TH}$, a biosynthetic enzyme for dopamine, to identify dopaminergic neurons. TH-positive neurons were quantified using unbiased stereology. At six to seven months after injection of $\alpha$-synuclein fibrils, there was an $\sim 50 \%$ bilateral loss of tyrosine-hydroxylase positive neurons in the $\mathrm{SNc}$ relative to mice injected with $\alpha$-synuclein monomer, consistent with previous reports in mice and rats (Luk et al., 2012; Paumier et al., 2015). There were no differences in THpositive neuron counts within genotype in either $\alpha$-synuclein monomer injected mice or $\alpha$-synuclein fibril mice.

\section{Behavior phenotypes depend on tau expression, both dependent and independent of $\alpha$-synuclein inclusion formation}

To determine whether Lewy-like inclusions correlated with behavioral phenotypes, we performed behavioral assays six months after injection. In the open field, tau heterozygous mice injected with fibrils showed lower total ambulatory distance than wild-type mice injected with fibrils (Fig. 5A). There were no significant differences among groups with respect to average velocity, or percent time in center, a measure of anxiety.

All mice successfully learned a fear conditioning paradigm (Fig. 5B). No group was significantly different from tau wild-type monomer mice at any time point during training; a three-way ANOVA revealed significant differences for genotype and time, but not treatment. In contextual fear conditioning, mice were re-exposed to the physical environment associated with the foot shock and freezing time was measured to determine memory of the adverse event. All groups of mice showed equivalent freezing behavior during contextual fear conditioning when compared with wild-type monomer mice. In cued fear conditioning, mice were placed in a novel environment and re-exposed to the auditory tone previously associated with the adverse stimulus. Statistical analysis using two-way ANOVA and post hoc tests revealed a significant difference between monomer injected wild-type and monomer injected knockout mice (Fig. 5B), tau knock-out monomer-injected mice froze significantly less than wild-type monomerinjected mice.

\section{Tau reduction does not prevent inclusion formation at 1.5 months after injection of $\alpha$-synuclein fibrils}

It was possible that six months after fibril injections, potential differences in the abundance of $\alpha$-synuclein inclusions are minimal at this late time point. However, analyzing an earlier time point after fibril injections could reveal differences among phenotypes. We therefore performed bilateral injections of $\alpha$-synuclein fibrils into the striatum and analyzed $\mathrm{p}$ - $\alpha$-synuclein inclusions 1.5 months later. We focused on wild-type and tau heterozygous mice because any therapeutic approach would reduce, but not completely remove, tau. The PFC, basolateral amygdala, and SNc showed robust formation of inclusions 1.5 months after striatal fibril injections (Fig. 6A). At this time point, $\alpha$-synuclein inclusions in the hippocampus were scant and restricted to small aggregates in the dentate gyrus. Quantitation of the inclusions revealed no significant differences between wild-type and tau heterozygous mice in any brain region (Fig. 6B). 
A

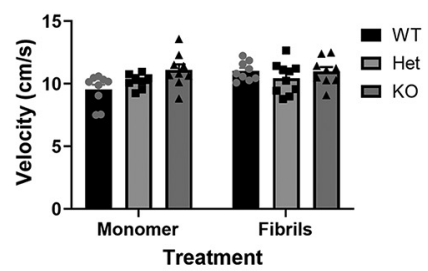

B

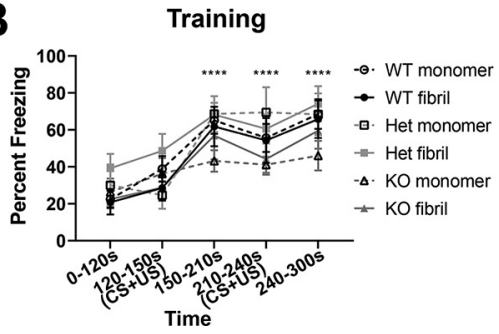

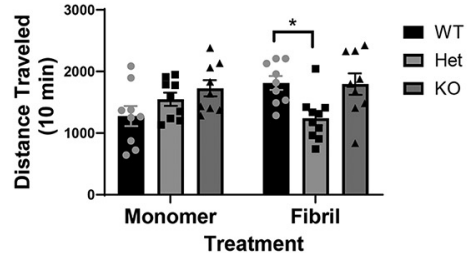

Treatment

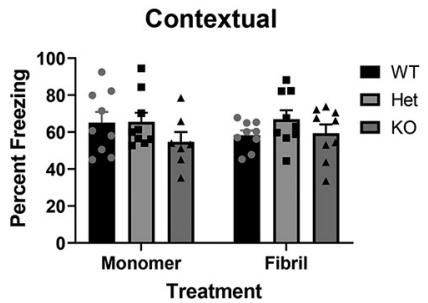

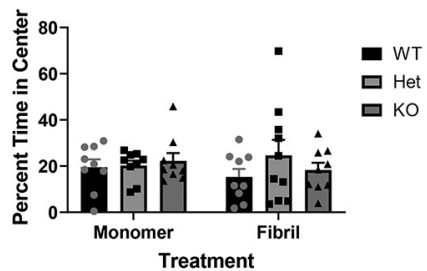

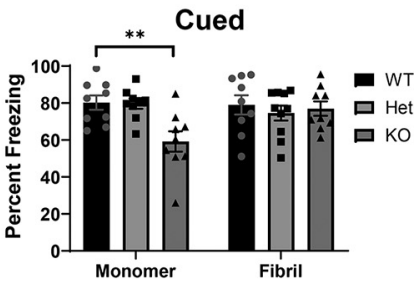

Figure 5. Mice underwent behavior testing five to six months after injection of monomer or fibrils. A, Analyses of open field test: velocity, total distance traveled $(\mathrm{cm})$, and percentage of time in center. Two-way ANOVA. Velocity, one outlier removed; interaction: $F_{(2,48)}=2.700, p=0.0774$; treatment: $F_{(1,48)}=3.248, p=0.0778$; genotype: $F_{(2,48)}=2.805, p=0.0705$. Distance traveled, interaction: $F_{(2,49)}=4.9, p=0.01$; treatment: $F_{(1,49)}=0.79, p=0.38$; genotype: $F_{(2,49)}=3.7, p=0.03$. Percent time in center, interaction: $F_{(2,49)}=$ 0.7311, $p=0.4866$; treatment: $F_{(1,49)}=0.1434, p=0.7066$; genotype: $F_{(2,49)}=0.7588, p=0.4736$. ${ }^{*} p<0.05$. $\boldsymbol{B}$, Training in fear conditioning paradigm and percentage time freezing in contextual and cued tests. Training: three-way ANOVA. Three-way interaction: $F_{(8,170)}=0.64, p=0.7449$; genotype $\times$ treatment: $F_{(2,170)}=0.9, p=0.4075$; genotype $\times$ time: $F_{(8,170)}=0.54, p=0.8246 ;$ treatment $\times$ time: $F_{(4,170)}=0.16, p=0.9583$; treatment: $F_{(1,170)}=0.76, p=0.385$; genotype: $F_{(2,170)}=7.44, p=0.0008$; time: $F_{(4,170)}=21.57$, $p<0.0001$. Contextual: two-way ANOVA. Interaction: $F_{(2,46)}=0.7843, p=0.4624$; treatment: $F_{(1,46)}=0.003584, p=0.9525$; genotype: $F_{(2,46)}=1.826, p=0.1725$. Cued: two-way ANOVA. Interaction: $F_{(2,49)}=4.003, p=0.0245 ;$ treatment: $F_{(1,49)}=1.171, p=0.2844$; genotype: $F_{(2,49)}=3.907, p=0.0266 .{ }^{* *} p<0.01$.

We performed behavioral assays 1.5 months after injection of fibrils. There were no significant differences between wild-type and tau heterozygous mice injected with monomer or fibrils in open field analyses including velocity, ambulatory distance and percent time in center (Fig. $6 C)$. All mice successfully learned a fear conditioning paradigm (Fig. 6D). No group was significantly different from tau wild-type monomer mice at any time point during training; a three-way ANOVA revealed significant differences for time, but not treatment or genotype. All groups of mice showed equivalent freezing behavior during contextual fear conditioning when compared with wild-type monomer mice. In cued fear conditioning, the tau heterozygous fibril-injected mice froze less than wild-type fibrilinjected mice.

\section{Discussion}

Here, we showed using PLA and expansion microscopy that tau and $\alpha$-synuclein both localize in presynaptic terminals, consistent with previous findings from synaptosome preparations from human brains, and consistent with in vitro studies showing that both proteins interact (Arima et al., 1999; Giasson et al., 2003; Galpern and Lang, 2006; Moussaud et al., 2014). However, reduction or complete absence of tau did not prevent fibril-induced $\alpha$-synuclein inclusion formation in primary hippocampal neurons or in vivo, in the cortex, amygdala, hippocampus, or SNc at either early or late time points after fibril injections, consistent with a previous report (Bassil et al.,
2021). Additionally, although we saw a robust, $\sim 50 \%$ loss of dopaminergic neurons in the SNc induced by $\alpha$-synuclein fibrils, reduction of tau did not prevent this loss. Lastly, reducing tau did not have any major impact behavioral phenotypes in mice with fibril-induced $\alpha$-synuclein inclusions.

Reducing tau in, human A53T- $\alpha$-synuclein $\alpha$-synuclein transgenic mice rescued cognitive behavioral phenotypes (Singh et al., 2019). This model relies on increased expression of mutant, human $\alpha$-synuclein. Expression of this rare $\alpha$-synuclein mutation forms Lewy-like aggregates in the cerebellum and pons but does not form insoluble aggregates in brain regions such as the cortex, amygdala or hippocampus. It is possible that the phenotypes such as impaired fear conditioning and synaptic defects are caused by increased expression of human A53T- $\alpha$-synuclein or small oligomers. While $\alpha$-synuclein gene multiplication and polymorphisms can slightly increase levels of $\alpha$-synuclein and cause PD (Singleton et al., 2003), it is currently unclear whether abnormal aggregation is a gain of toxic function or a loss of function. Our lab previously showed that early formation of seeded $\alpha$-synuclein inclusions causes an initial increase in synaptic vesicle release (Froula et al., 2018). Normally, $\alpha$-synuclein acts as a brake on release of synaptic vesicles (Sun et al., 2019) and thus, our data point to aggregation as a loss of $\alpha$-synuclein function. Also, our data are consistent with other studies showing that reduction of tau in mice expressing human wild-type $\alpha$-synuclein was not effective in preventing motor defects (Morris et al., 2011). 
A

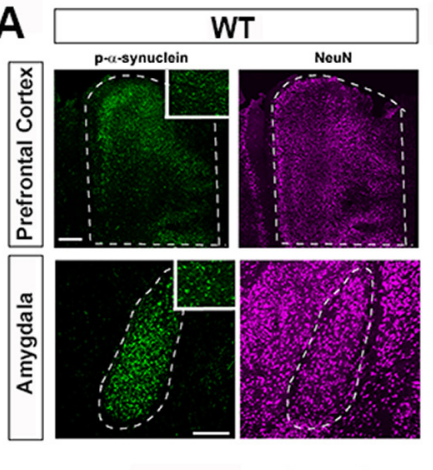

B

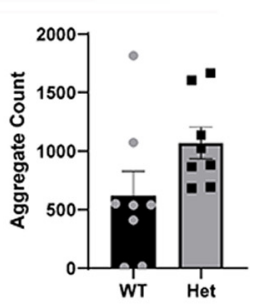

C

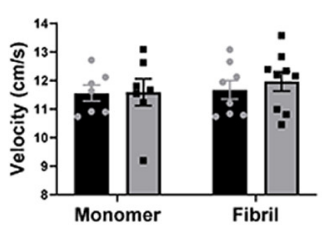

D

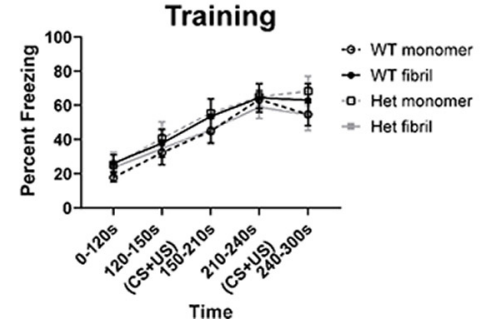

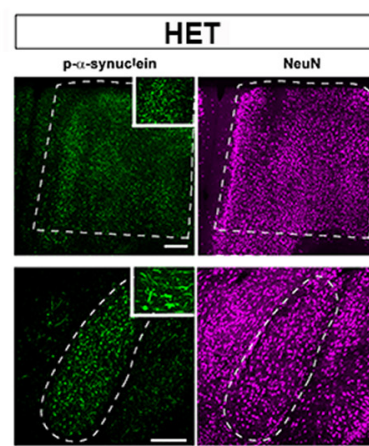

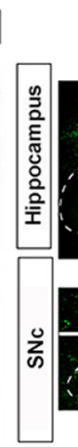

Basolateral Amygdala
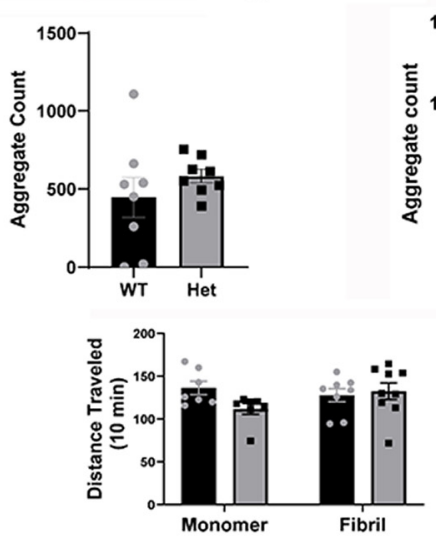

Contextual

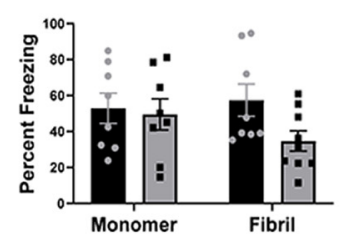

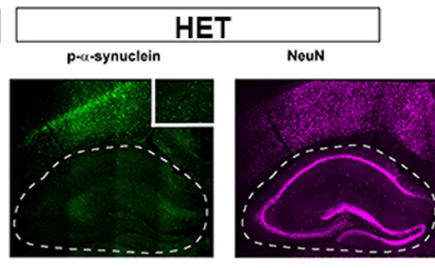
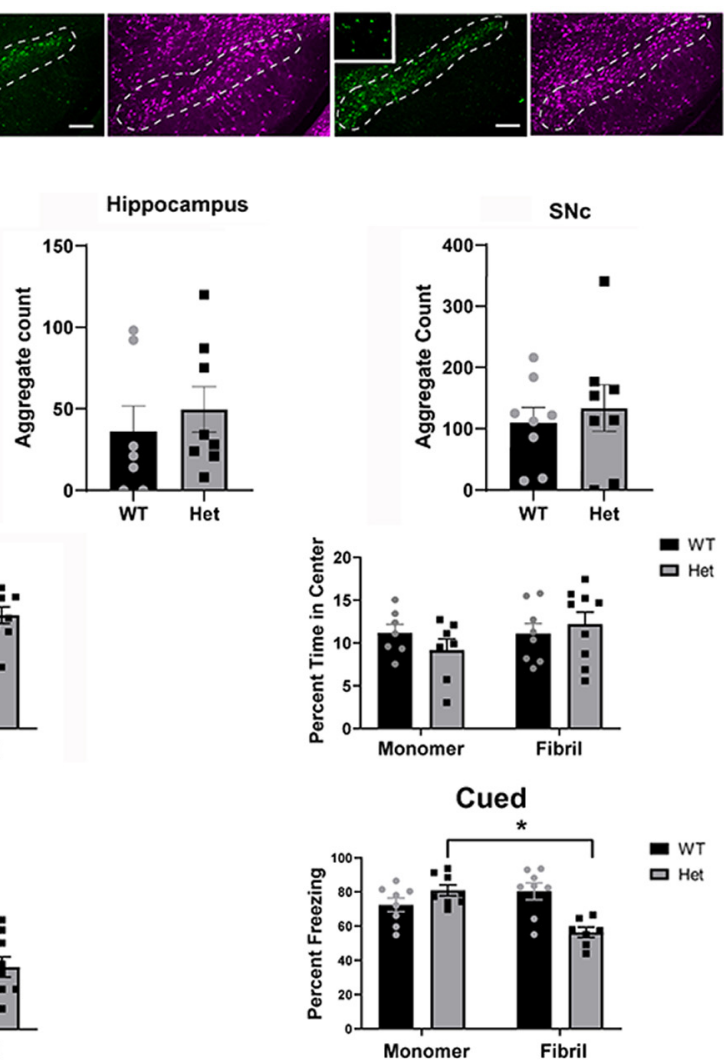

Figure 6. $\boldsymbol{A}$, One and a half months after bilateral striatal injection of $\alpha$-synuclein fibrils, mice were perfused and immunofluorescence to $\mathrm{p}$ - $\alpha$-synuclein was performed. Images were captured using confocal microscopy and $\mathrm{p}$ - $\alpha$-inclusions were quantified using Fiji. Higher magnification insets in each panel show inclusions. B, Quantification of PFC (left), basolateral amygdala (center left), hippocampus (center right) and SNc (right). PFC: independent $t$ test, $t_{(14)}=1.8, p=0.09$. Basolateral amygdala: independent $t$ test, $t_{(14)}=1.02, p=0.32$. Hippocampus, $t_{(13)}=0.65, p=0.52$. SNc $t_{(14)}=0.53, p=0.6 . N=8-10 /$ group. Scale bars: $250 \mu \mathrm{m}$. $\boldsymbol{C}$, Analyses of open field test: velocity, total distance traveled $(\mathrm{cm})$, and percentage of time in center. Two-way ANOVA. Velocity, interaction: $F_{(1,27)}=3.1, p=0.09$; treatment: $F_{(1,27)}=0.5, p=0.5$; genotype: $F_{(1,27)}=1.4, p=0.24$. Distance traveled, interaction: $F_{(1,27)}=0.13$, $p=0.71$; treatment: $F_{(1,27)}=0.47, p=0.49$; genotype: $F_{(1,27)}=0.2, p=0.65$. Percent time in center, interaction: $F_{(1,27)}=1.5, p=0.23$; treatment: $F_{(1,27)}=1.3, p=0.26$; genotype: $F_{(1,2)}=0.12, p=0.72$. $\boldsymbol{D}$, Training in fear conditioning paradigm and percentage time freezing in contextual and cued tests. Training: three-way ANOVA. Three-way interaction: $F_{(16,120)}=0.8, p=0.67$; genotype $\times$ treatment: $F_{(4,30)}=0.5, p=0.71$; time: $F_{(2,88)}=42.8, \mathrm{p}<0.0001$. Contextual: two-way ANOVA. Interaction: $F_{(1,29)}=1.4, p=0.23$; treatment: $F_{(1,27)}=0.43, p=0.51$; genotype: $F_{(1,29)}=2.8, p=0.11$. Cued: two-way ANOVA. Interaction: $F_{(1,27)}=17.52, p=0.0003$; treatment: $F_{(1,27)}=4.5, p=0.04$; genotype: $F_{(1,27)}=3.9, p=0.05$. ${ }^{*} p<0.05$.

Overall, our results indicate that endogenous tau does not play a role in seeded $\alpha$-synuclein inclusion formation. However, because tau pathology is present in a subset of patients with $P D$, it is possible that abnormal tau assemblies are playing a role in PD phenotypes and that reduction of oligomers may be protective (Gerson et al., 2018).

It is essential to consider the limitations of the current study and the degree to which it recapitulates human LBDs. First, we cannot exclude the possibility that embryonic knock-out or partial reduction of tau induces a compensatory mechanism by which a potential effect of tau is negated. To counter this, an inducible tau knockout line or tau antisense oligonucleotides could be beneficial. Additionally, any extrapolation to human disease is limited in the etiology of sporadic LBD, as our model "skips" the initial insult and multifactorial causes of the disease via intracerebral injection to induce Lewy-like pathology. Our data suggest that tau does not play a significant role after the initial insult, but it remains possible that tau may affect the initial misfolding of $\alpha$-synuclein. 
Our behavioral data showed that homozygous tau knock-out caused defects in cued fear conditioning in aged (nine month) mice which has been demonstrated previously (Ikegami et al., 2000; Ahmed et al., 2014; Goncalves et al., 2020) and may be related to their tendency toward hyperactivity, since other learning and memory tests are not impaired. Tau heterozygous (but not tau knock-out) mice injected with fibrils showed defects compared with control mice in cued fear conditioning at an early time point following injections. Our findings that tau reduction does not rescue behavioral phenotypes support previous studies showing that tau reduction does not improve behavioral phenotypes in 6-hydroxydopamine or MPTP lesion models, or in $\alpha$-synuclein transgenic mice (Morris et al., 2011; Gratuze et al., 2019). However, antibodies directed to tau oligomers do show protection in $\alpha$-synuclein models and it therefore remains possible that tau immunotherapy may be protective in synucleinopathies with co-existing pathologic aggregates of tau (Gerson et al., 2018).

Tau reduction is an attractive avenue for potential therapeutics in multiple neurodegenerative diseases because of its role in aggregation, potential as a biomarker, and avenue for immunotherapy (Gerson et al., 2018). Indeed, studies using transgenic lines for $A D$ and tauopathies have shown that approach to be promising (Roberson et al., 2007; DeVos et al., 2018). However, the results of this study suggest the role of tau in LBDs may not be as forthright as in $A D$, and the two spectra of diseases may have distinct pathogenesis as far as tau is concerned. Data here suggests that any role of endogenous, physiologic tau (at least in a murine model) is upstream to the fibrillization of $\alpha$-synuclein pathology. Additional studies are needed to further explore the therapeutic benefit of tau reduction in LBDs, but these results suggest that Lewy-like pathology is independent of tau.

\section{References}

Abdelmotilib H, Maltbie T, Delic V, Liu Z, Hu X, Fraser KB, Moehle MS, Stoyka L, Anabtawi N, Krendelchtchikova V, Volpicelli-Daley LA, West A (2017) $\alpha$-Synuclein fibril-induced inclusion spread in rats and mice correlates with dopaminergic neurodegeneration. Neurobiol Dis 105:84-98.

Ahmed T, Van der Jeugd A, Blum D, Galas MC, D'Hooge R, Buee L, Balschun D (2014) Cognition and hippocampal synaptic plasticity in mice with a homozygous tau deletion. Neurobiol Aging 35:2474-2478.

Arima K, Hirai S, Sunohara N, Aoto K, Izumiyama Y, Uéda K, Ikeda K, Kawai M (1999) Cellular co-localization of phosphorylated tau- and NACP/alpha-synuclein-epitopes in lewy bodies in sporadic Parkinson's disease and in dementia with Lewy bodies. Brain Res 843:53-61.

Asano SM, Gao R, Wassie AT, Tillberg PW, Chen F, Boyden ES (2018) Expansion microscopy: protocols for imaging proteins and RNA in cells and tissues. Curr Protoc Cell Biol 80:e56.

Bassil F, Meymand ES, Brown HJ, Xu H, Cox TO, Pattabhiraman S, Maghames CM, Wu Q, Zhang B, Trojanowski JQ, Lee VMY (2021) $\alpha$-Synuclein modulates tau spreading in mouse brains. J Exp Med 218:e20192193.

Blauwendraat C, Nalls MA, Singleton AB (2020) The genetic architecture of Parkinson's disease. Lancet Neurol 19:170-178.

Bousset L, Pieri L, Ruiz-Arlandis G, Gath J, Jensen PH, Habenstein B, Madiona K, Olieric V, Böckmann A, Meier BH, Melki R (2013)
Structural and functional characterization of two alpha-synuclein strains. Nat Commun 4:2575.

Braak H, Del Tredici K, Rüb U, de Vos RA, Jansen Steur EN, Braak E (2003) Staging of brain pathology related to sporadic Parkinson's disease. Neurobiol Aging 24:197-211.

Braak H, Rub U, Jansen Steur EN, Del Tredici K, de Vos RA (2005) Cognitive status correlates with neuropathologic stage in Parkinson disease. Neurology 64:1404-1410.

Chen F, Tillberg PW, Boyden ES (2015) Optical imaging. Expansion microscopy. Science 347:543-548.

Colom-Cadena M, Pegueroles J, Herrmann AG, Henstridge CM, Muñoz L, Querol-Vilaseca M, Martín-Paniello CS, LuqueCabecerans J, Clarimon J, Belbin O, Núñez-Llaves R, Blesa R, Smith C, McKenzie CA, Frosch MP, Roe A, Fortea J, Andilla J, Loza-Alvarez P, Gelpi E, et al. (2017) Synaptic phosphorylated $\alpha$-synuclein in dementia with Lewy bodies. Brain 140:3204-3214.

Coughlin D, Xie SX, Liang M, Williams A, Peterson C, Weintraub D, McMillan CT, Wolk DA, Akhtar RS, Hurtig HI, Branch Coslett H, Hamilton RH, Siderowf AD, Duda JE, Rascovsky K, Lee EB, Lee VM, Grossman M, Trojanowski JQ, et al. (2019) Cognitive and pathological influences of tau pathology in Lewy body disorders. Ann Neurol 85:259-271.

Dasari AKR, Kayed R, Wi S, Lim KH (2019) Tau interacts with the Cterminal region of $\alpha$-synuclein, promoting formation of toxic aggregates with distinct molecular conformations. Biochemistry 58:2814-2821.

Dawson HN, Ferreira A, Eyster MV, Ghoshal N, Binder LI, Vitek MP (2001) Inhibition of neuronal maturation in primary hippocampal neurons from tau deficient mice. J Cell Sci 114:1179-1187.

Del Tredici K, Braak H (2013) Dysfunction of the locus coeruleus-norepinephrine system and related circuitry in Parkinson's diseaserelated dementia. J Neurol Neurosurg Psychiatry 84:774-783.

Delic V, Chandra S, Abdelmotilib H, Maltbie T, Wang S, Kem D, Scott HJ, Underwood RN, Liu Z, Volpicelli-Daley LA, West AB (2018) Sensitivity and specificity of phospho-Ser129 $\alpha$-synuclein monoclonal antibodies. J Comp Neurol 526:1978-1990.

DeVos SL, Miller RL, Schoch KM, Holmes BB, Kebodeaux CS, Wegener AJ, Chen G, Shen T, Tran H, Nichols B, Zanardi TA, Kordasiewicz HB, Swayze EE, Bennett CF, Diamond MI, Miller TM (2017) Tau reduction prevents neuronal loss and reverses pathological tau deposition and seeding in mice with tauopathy. Sci Transl Med 9:eaag0481.

DeVos SL, Corjuc BT, Commins C, Dujardin S, Bannon RN, Corjuc D, Moore BD, Bennett RE, Jorfi M, Gonzales JA, Dooley PM, Roe AD, Pitstick R, Irimia D, Frosch MP, Carlson GA, Hyman BT (2018) Tau reduction in the presence of amyloid- $\beta$ prevents tau pathology and neuronal death in vivo. Brain 141:2194-2212.

Duda JE, Giasson BI, Mabon ME, Miller DC, Golbe LI, Lee VM, Trojanowski JQ (2002) Concurrence of $\alpha$-synuclein and tau brain pathology in the Contursi kindred. Acta Neuropathol 104:7-11.

Fletcher TL, De Camilli P, Banker G (1994) Synaptogenesis in hippocampal cultures: evidence indicating that axons and dendrites become competent to form synapses at different stages of neuronal development. J Neurosci 14:6695-6706.

Froula JM, Henderson BW, Gonzalez JC, Vaden JH, McLean JW, Wu Y, Banumurthy G, Overstreet-Wadiche L, Herskowitz JH, Volpicelli-Daley LA (2018) $\alpha$-Synuclein fibril-induced paradoxical structural and functional defects in hippocampal neurons. Acta Neuropathol Commun 6:35.

Froula JM, Castellana-Cruz M, Anabtawi NM, Camino JD, Chen SW, Thrasher DR, Freire J, Yazdi AA, Fleming S, Dobson CM, Kumita JR, Cremades N, Volpicelli-Daley LA (2019) Defining $\alpha$-synuclein species responsible for Parkinson's disease phenotypes in mice. J Biol Chem 294:10392-10406.

Fu H, Possenti A, Freer R, Nakano Y, Hernandez Villegas NC, Tang M, Cauhy PVM, Lassus BA, Chen S, Fowler SL, Figueroa HY, Huey ED, Johnson GVW, Vendruscolo M, Duff KE (2019) A tau homeostasis signature is linked with the cellular and regional vulnerability of excitatory neurons to tau pathology. Nat Neurosci 22:47-56. 
Fujiwara H, Hasegawa M, Dohmae N, Kawashima A, Masliah E, Goldberg MS, Shen J, Takio K, Iwatsubo T (2002) $\alpha$-Synuclein is phosphorylated in synucleinopathy lesions. Nat Cell Biol 4:160164.

Galpern WR, Lang AE (2006) Interface between tauopathies and synucleinopathies: a tale of two proteins. Ann Neurol 59:449-458.

Gerson JE, Farmer KM, Henson N, Castillo-Carranza DL, Carretero Murillo M, Sengupta U, Barrett A, Kayed R (2018) Tau oligomers mediate $\alpha$-synuclein toxicity and can be targeted by immunotherapy. Mol Neurodegener 13:13.

Giasson BI, Forman MS, Higuchi M, Golbe LI, Graves CL, Kotzbauer PT, Trojanowski JQ, Lee VM (2003) Initiation and synergistic fibrillization of tau and alpha-synuclein. Science 300:636-640.

Goncalves RA, Wijesekara N, Fraser PE, De FF (2020) Behavioral abnormalities in knockout and humanized tau mice. Front Endocrinol (Lausanne) 11:124.

Gratuze M, Josset N, Petry FR, Pflieger M, Eyoum Jong L, Truchetti G, Poitras I, Julien J, Bezeau F, Morin F, Samadi P, Cicchetti F, Bretzner F, Planel E (2019) The toxin MPTP generates similar cognitive and locomotor deficits in hTau and tau knock-out mice. Brain Res 1711:106-114.

Hall H, Reyes S, Landeck N, Bye C, Leanza G, Double K, Thompson L, Halliday G, Kirik D (2014) Hippocampal Lewy pathology and cholinergic dysfunction are associated with dementia in Parkinson's disease. Brain 137:2493-2508.

Harms AS, Cao S, Rowse AL, Thome AD, Li X, Mangieri LR, Cron $R Q$, Shacka JJ, Raman C, Standaert DG (2013) MHCIl is required for $\alpha$-synuclein-induced activation of microglia, CD4 T cell proliferation, and dopaminergic neurodegeneration. J Neurosci 33:95929600.

Ikegami S, Harada A, Hirokawa N (2000) Muscle weakness, hyperactivity, and impairment in fear conditioning in tau-deficient mice. Neurosci Lett 279:129-132.

Irwin DJ, Grossman M, Weintraub D, Hurtig HI, Duda JE, Xie SX, Lee EB, Van Deerlin VM, Lopez OL, Kofler JK, Nelson PT, Jicha GA, Woltjer R, Quinn JF, Kaye J, Leverenz JB, Tsuang D, Longfellow K, Yearout D, Kukull W, et al. (2017) Neuropathological and genetic correlates of survival and dementia onset in synucleinopathies: a retrospective analysis. Lancet Neurol 16:55-65.

Ishizawa T, Mattila P, Davies P, Wang D, Dickson DW (2003) Colocalization of tau and alpha-synuclein epitopes in Lewy bodies. J Neuropathol Exp Neurol 62:389-397.

Jellinger KA (2009) Formation and development of Lewy pathology: a critical update. J Neurol 256 [Suppl 3]:270-279.

Jellinger KA, Korczyn AD (2018) Are dementia with Lewy bodies and Parkinson's disease dementia the same disease? BMC Med 16:34.

Jiao L, Zheng M, Duan J, Wu T, Li Z, Liu L, Xiang X, Tang X, He J, Li $X$, Zhang G, Ding J, Cai H, Lin X (2020) Tau knockout exacerbates degeneration of parvalbumin-positive neurons in substantia nigra pars reticulata in Parkinson's disease-related $\alpha$-synuclein A53T mice. FASEB J 34:12239-12254.

Karpowicz RJ Jr, Haney CM, Mihaila TS, Sandler RM, Petersson EJ, Lee VM (2017) Selective imaging of internalized proteopathic $\alpha$-synuclein seeds in primary neurons reveals mechanistic insight into transmission of synucleinopathies. J Biol Chem 292:1348213497.

Luk KC, Kehm V, Carroll J, Zhang B, O’Brien P, Trojanowski JQ, Lee VM (2012) Pathological $\alpha$-synuclein transmission initiates Parkinson-like neurodegeneration in nontransgenic mice. Science 338:949-953.

Mattila PM, Röyttä M, Torikka H, Dickson DW, Rinne JO (1998) Cortical Lewy bodies and Alzheimer-type changes in patients with Parkinson's disease. Acta Neuropathol 95:576-582.

Mclnnes J, Wierda K, Snellinx A, Bounti L, Wang YC, Stancu IC, Apóstolo N, Gevaert K, Dewachter I, Spires-Jones TL, De Strooper B, De Wit J, Zhou L, Verstreken P (2018) Synaptogyrin-3 mediates presynaptic dysfunction induced by tau. Neuron 97:823-835.e8.
Morris M, Koyama A, Masliah E, Mucke L (2011) Tau reduction does not prevent motor deficits in two mouse models of Parkinson's disease. PLoS One 6:e29257.

Moussaud S, Jones DR, Moussaud-Lamodière EL, Delenclos M, Ross OA, McLean PJ (2014) Alpha-synuclein and tau: teammates in neurodegeneration? Mol Neurodegener 9:43.

Murphy DD, Rueter SM, Trojanowski JQ, Lee VM (2000) Synucleins are developmentally expressed, and alpha-synuclein regulates the size of the presynaptic vesicular pool in primary hippocampal neurons. J Neurosci 20:3214-3220.

Osterberg VR, Spinelli KJ, Weston LJ, Luk KC, Woltjer RL, Unni VK (2015) Progressive aggregation of alpha-synuclein and selective degeneration of lewy inclusion-bearing neurons in a mouse model of parkinsonism. Cell Rep 10:1252-1260.

Patterson JR, Duffy MF, Kemp CJ, Howe JW, Collier TJ, Stoll AC, Miller KM, Patel P, Levine N, Moore DJ, Luk KC, Fleming SM, Kanaan NM, Paumier KL, El-Agnaf OMA, Sortwell CE (2019) Time course and magnitude of alpha-synuclein inclusion formation and nigrostriatal degeneration in the rat model of synucleinopathy triggered by intrastriatal alpha-synuclein preformed fibrils. Neurobiol Dis 130:104525.

Paumier KL, Luk KC, Manfredsson FP, Kanaan NM, Lipton JW, Collier TJ, Steece-Collier K, Kemp CJ, Celano S, Schulz E, Sandoval IM, Fleming S, Dirr E, Polinski NK, Trojanowski JQ, Lee VM, Sortwell CE (2015) Intrastriatal injection of pre-formed mouse $\alpha$-synuclein fibrils into rats triggers $\alpha$-synuclein pathology and bilateral nigrostriatal degeneration. Neurobiol Dis 82:185-199.

Pelayo JC, Poole DP, Steinhoff M, Cottrell GS, Bunnett NW (2011) Endothelin-converting enzyme-1 regulates trafficking and signalling of the neurokinin 1 receptor in endosomes of myenteric neurones. J Physiol 589:5213-5230.

Roberson ED, Scearce-Levie K, Palop JJ, Yan F, Cheng IH, Wu T, Gerstein H, Yu GQ, Mucke L (2007) Reducing endogenous tau ameliorates amyloid beta-induced deficits in an Alzheimer's disease mouse model. Science 316:750-754.

Schmitz C (1998) Variation of fractionator estimates and its prediction. Anat Embryol (Berl) 198:371-397.

Singh B, Covelo A, Martell-Martínez H, Nanclares C, Sherman MA, Okematti E, Meints J, Teravskis PJ, Gallardo C, Savonenko AV, Benneyworth MA, Lesné SE, Liao D, Araque A, Lee MK (2019) Tau is required for progressive synaptic and memory deficits in a transgenic mouse model of $\alpha$-synucleinopathy. Acta Neuropathol 138:551-574.

Singleton $A B$, Singleton $A B$, Farrer $M$, Johnson J, Singleton $A$, Hague $S$, Kachergus J, Hulihan M, Peuralinna T, Dutra A, Nussbaum R, Lincoln S, Crawley A, Hanson M, Maraganore D, Adler C, Cookson MR, Muenter M, Baptista M, Miller D, Blancato $J$, et al. (2003) $\alpha$-Synuclein locus triplication causes Parkinson's disease. Science 302:841.

Söderberg O, Leuchowius KJ, Gullberg M, Jarvius M, Weibrecht I, Larsson LG, Landegren U (2008) Characterizing proteins and their interactions in cells and tissues using the in situ proximity ligation assay. Methods 45:227-232.

Sorrentino ZA, Goodwin MS, Riffe CJ, Dhillon JS, Xia Y, Gorion KM, Vijayaraghavan N, McFarland KN, Golbe LI, Yachnis AT, Giasson BI (2019) Unique $\alpha$-synuclein pathology within the amygdala in Lewy body dementia: implications for disease initiation and progression. Acta Neuropathol Commun 7:142.

Spillantini MG, Schmidt ML, Lee VM, Trojanowski JQ, Jakes R, Goedert M (1997) Alpha-synuclein in Lewy bodies. Nature 388:839-840.

Spillantini MG, Crowther RA, Jakes R, Hasegawa M, Goedert M (1998) $\alpha$-Synuclein in filamentous inclusions of Lewy bodies from Parkinson's disease and dementia with lewy bodies. Proc Natl Acad Sci USA 95:6469-6473.

Stoyka LE, Arrant AE, Thrasher DR, Russell DL, Freire J, Mahoney CL, Narayanan A, Dib AG, Standaert DG, Volpicelli-Daley LA (2020) Behavioral defects associated with amygdala and cortical dysfunction in mice with seeded $\alpha$-synuclein inclusions. Neurobiol Dis 134:104708. 
Sun J, Wang L, Bao H, Premi S, Das U, Chapman ER, Roy S (2019) Functional cooperation of $\alpha$-synuclein and VAMP2 in synaptic vesicle recycling. Proc Natl Acad Sci USA 116:11113-11115.

Taguchi K, Watanabe Y, Tsujimura A, Tanaka M (2016) Brain regiondependent differential expression of alpha-synuclein. J Comp Neurol 524:1236-1258.

Tillberg PW, Chen F, Piatkevich KD, Zhao Y, Yu CC, English BP, Gao L, Martorell A, Suk HJ, Yoshida F, DeGennaro EM, Roossien DH, Gong G, Seneviratne U, Tannenbaum SR, Desimone R, Cai D, Boyden ES (2016) Protein-retention expansion microscopy of cells and tissues labeled using standard fluorescent proteins and antibodies. Nat Biotechnol 34:987-992.

Volpicelli-Daley LA, Luk KC, Patel TP, Tanik SA, Riddle DM, Stieber A, Meaney DF, Trojanowski JQ, Lee VM (2011) Exogenous $\alpha$-synuclein fibrils induce Lewy body pathology leading to synaptic dysfunction and neuron death. Neuron 72:57-71.
Volpicelli-Daley LA, Luk KC, Lee VM (2014a) Addition of exogenous $\alpha$-synuclein preformed fibrils to primary neuronal cultures to seed recruitment of endogenous $\alpha$-synuclein to Lewy body and Lewy neurite-like aggregates. Nat Protoc 9:2135-2146.

Volpicelli-Daley LA, Gamble KL, Schultheiss CE, Riddle DM, West $\mathrm{AB}$, Lee VM (2014b) Formation of $\alpha$-synuclein Lewy neurite-like aggregates in axons impedes the transport of distinct endosomes. Mol Biol Cell 25:4010-4023.

Wassie AT, Zhao Y, Boyden ES (2019) Expansion microscopy: principles and uses in biological research. Nat Methods 16:3341.

Zhou L, Mclnnes J, Wierda K, Holt M, Herrmann AG, Jackson RJ, Wang YC, Swerts J, Beyens J, Miskiewicz K, Vilain S, Dewachter I, Moechars D, De Strooper B, Spires-Jones TL, De Wit J, Verstreken P (2017) Tau association with synaptic vesicles causes presynaptic dysfunction. Nat Commun 8:15295. 